\title{
LARGE-SCALE EVALUATION OF NICKEL ALUMINIDE ROLLS IN A HEAT-TREAT FURNACE AT BETHLEHEM STEEL'S (NOW ISG) BURNS HARBOR PLATE MILL
}

Bethlehem Steel Corporation (ISG)

John Mengel

Anthony Martocci

Larry Fabina

Robert Petrusha

Ronald Chango

Oak Ridge National Laboratory

Peter Angelini

Vinod Sikka

Michael Santella 


\section{ACKNOWLEDGEMENTS}

This project was conducted under Contract Agreement Number DE-FC07-02ID14316 from the Idaho Office of the U.S. Department of Energy, as part of the U.S. DOE, Office of Industrial Technology's Emerging Technology Deployment Program.

Sincere appreciation is extended to the U.S. Department of Energy, Office of Industrial Technologies for their support of new technologies by partnering with Bethlehem Steel (ISG)and Oak Ridge National Laboratories to demonstrate and evaluate the nickel aluminide intermetallic alloy rolls as part of an updated energy efficient large commercial annealing furnace system.

Many challenges were involved in this project, including developing welding procedures for joining nickel aluminide intermetallic alloys with $\mathrm{H}$-series austenitic alloys, developing commercial cast roll manufacturing specifications, working with several commercial suppliers to produce a quantity of high quality, reproducible nickel aluminide rolls for a large steel industrial annealing furnace, installing and demonstrating the capability of the rolls in this furnace, performing processing trials to evaluate the benefits of new equipment and processes, and documenting the findings; all within a one-year time frame. Special thanks are offered to the Bethlehem Steel Burns Harbor (ISG) and Oak Ridge National Laboratory employees who worked through the problems and difficulties encountered. Additional thanks are extended to suppliers Duraloy Technologies, Inc. and Ultra-Cast, Inc. and their employees for their input and effort in working through the learning curve of new manufacturing specifications and process techniques. 
ACKNOWLEDGEMENT

1. EXECUTIVE SUMMARY. .5

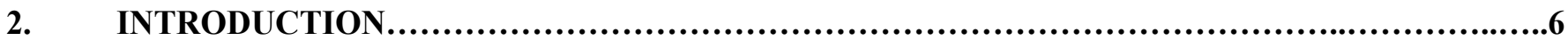

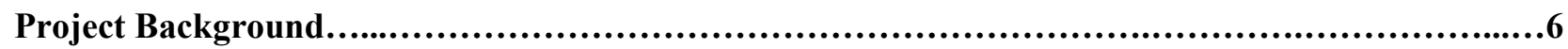

Nickel Aluminide Alloy Background................................................................8

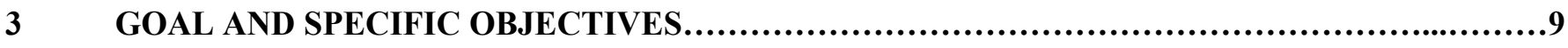

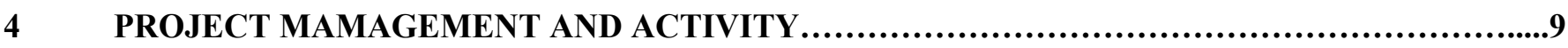

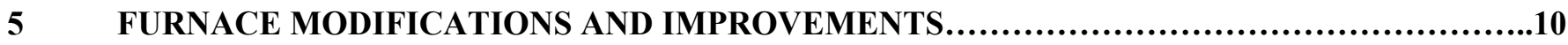

Updated Furnace Flame Safety Controls............................................................10

Improved Dampers and Controls....................................................................

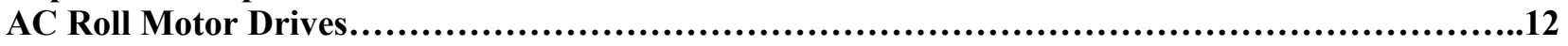

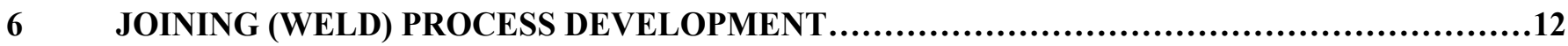

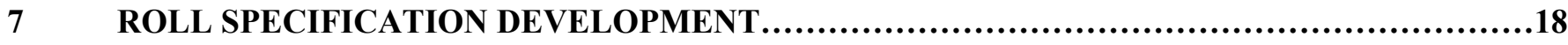

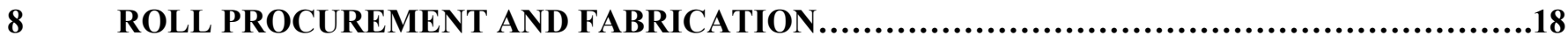

Supplier Selection Process.......................................................................18

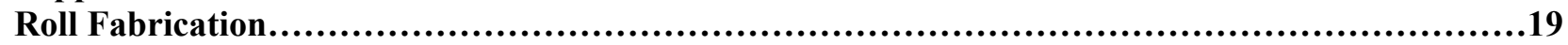

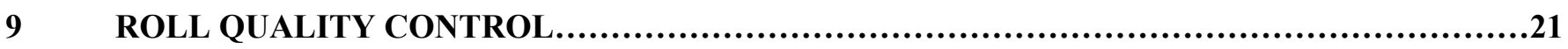

Field Inspections Before Roll Shipment..........................................................21

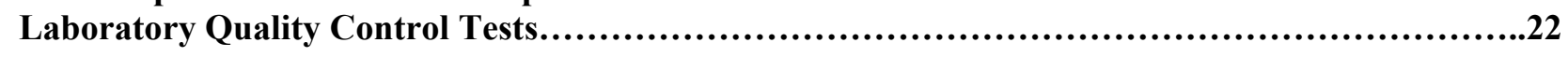

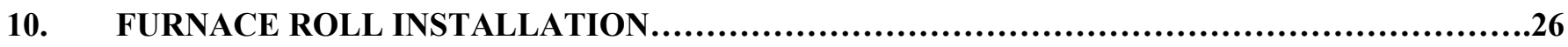

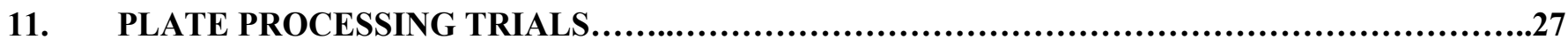

12 FURNACE ROLL AND ENERGY PERFORMANCE..............................................29

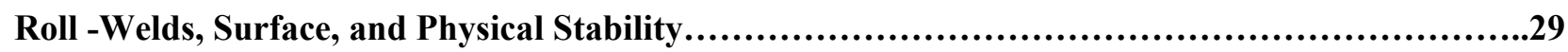

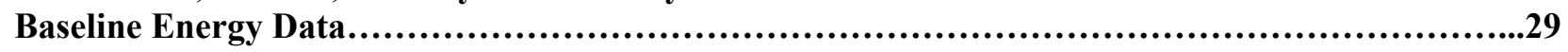

Post Damper Installation Energy Data............................................................30

Extended Heating Campaign Energy Data......................................................31

Straight-Through Plate Processing Energy Data.....................................................

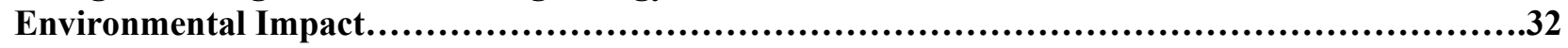

Cost Competitiveness..............................................................................

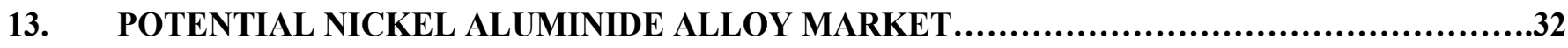

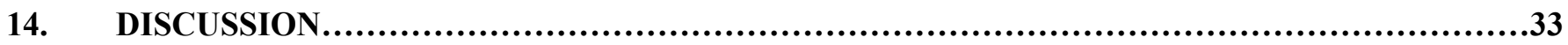

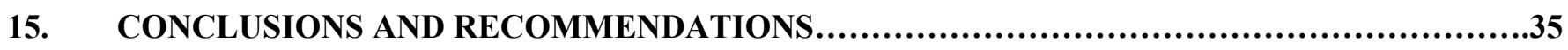

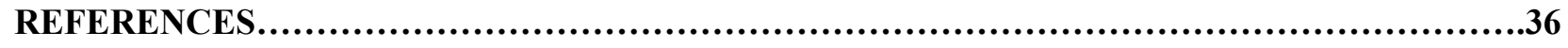

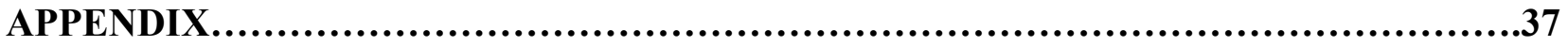




\section{ABSTRACT}

At Bethlehem Steel Burns Harbor Plate Division (now ISG Burns Harbor Plate Inc.)'s annealing furnace, new nickel aluminide intermetallic alloy rolls provide greater high-temperature strength and wear resistance compared to the conventional $H$ series cast austenitic alloys currently used in the industry. Oak Ridge National Laboratory and Bethlehem (ISG) partnered under a U.S. Department of Energy, Office of Industrial Technology's Emerging Technology Deployment Program to demonstrate and evaluate the nickel aluminide intermetallic alloy rolls as part of an updated energy efficient large commercial annealing furnace system.

Many challenges were involved in this project, including developing welding procedures for joining nickel aluminide intermetallic alloys with $\mathrm{H}$-series austenitic alloys, developing commercial cast roll manufacturing specifications, working with several commercial suppliers to produce a quantity of high quality, reproducible nickel aluminide rolls for a large steel industrial annealing furnace, installing and demonstrating the capability of the rolls in this furnace, performing processing trials to evaluate the benefits of new equipment and processes, and documenting the findings.

Updated furnace equipment including twenty-five new automated furnace control dampers have been installed replacing older design, less effective units. These dampers, along with upgraded flame-safety control equipment and new AC motors and roll-speed control equipment, are providing improved furnace control and additional energy efficiency.

Energy data shows up to a $34 \%$ energy reduction from baseline after the installation of upgraded furnace damper controls along with up to a $34 \%$ reduction in greenhouse gases, potential for an additional 3 to $6 \%$ energy reduction per campaign of light-up and shutdown, and a $46 \%$ energy reduction from baseline for limited trials of a combination of improved damper control and straight-through plate processing. The straight-through processing is now possible because of the nickel aluminide rolls which also provided plate product surface quality improvement that will allow the additional processing of surface critical material. Benefits also include associated large reductions in maintenance, reduction in spare rolls and associated component costs, and potential for greater through-put and productivity.

Estimated project fuel cost reductions alone for processing 100,000 tons/yr through this furnace are almost $\$ 0.5 \mathrm{million} / \mathrm{yr}$ with the new dampers, and more than $\$ 600,000 / \mathrm{yr}$ with straightthrough processing and new damper control, assuming natural gas prices of $\$ 6.00 / \mathrm{MMBtu}$.

The nickel aluminide rolls are competitively priced with conventional H series alloy rolls. 


\section{EXECUTIVE SUMMARY}

Conclusions are that commercialization of the nickel aluminide alloy through fabrication of full-size furnace rolls has been demonstrated and their effectiveness in an overall improved energy efficient furnace system documented. Project objectives have been met. Recommendations are to continue roll performance analysis for additional lifeexpectancy data and expanded roll operating parameters such as higher furnace temperature, along with technical assistance in expanded utilization of this alloy in new products and markets.

Energy data shows up to a $34 \%$ energy reduction from baseline after the installation of upgraded furnace damper controls, ( 0.77 MMBtu/ton), along with up to a $34 \%$ reduction in greenhouse gases, potential for an additional 3 to $6 \%$ energy reduction per campaign of light-up and shutdown, and a $46 \%$ energy reduction from baseline for limited trials of a combination of improved damper control and straight-through plate processing, ( 1.06 MMBtu/ton). The limited straight-through processing provided improved plate product surfaces that will allow the additional processing of surface critical material.

Benefits also include associated reductions in maintenance, reduction in spare rolls and associated component costs, and potential for greater through-put and productivity.

Estimated project energy cost reductions for processing 100,000 tons/yr are almost $\$ 0.5$ million/yr with the new dampers alone and more than $\$ 600,000 / y r$ with straightthrough processing and new damper control, assuming natural gas prices of $\$ 6.00 / \mathrm{MMBtu}$.

Bethlehem Steel (now ISG) continued its energy history of proactive partnering by joining with Oak Ridge National Laboratories under the U.S. Department of Energy, Office of Industrial Technology's Emerging Technology Deployment Program to demonstrate a new nickel aluminide alloy technology related to energy efficiency. When tied to other proven equipment, this new technology provided a more energy efficient furnace system, reduced environmental impact, and improved economic competitiveness.

A quantity of nickel aluminide intermetallic alloy rolls were manufactured by two commercial suppliers at cost competitive prices. Thirty of these rolls were installed in a large commercial annealing furnace at Burns Harbor Plate (ISG) to demonstrate the commercial fabricability, high temperature strength, material stability, wear resistance, and cost effectiveness of this alloy along with associated energy, environmental, productivity, and cost improvements. Teams from Bethlehem Steel (ISG) and Oak Ridge National Laboratories worked together to develop joining procedures and commercial roll fabrication specifications, assist in roll fabrication techniques with two commercial suppliers - Duraloy, Inc., and Ultra-Cast, Inc., install the rolls in the annealing furnace, and demonstrate and evaluate the roll performance in this large commercial annealing furnace. In addition, improvements were made to the furnace as part of a total energy system that allows process changes which, in conjunction with the nickel aluminide rolls, further reduces energy consumption, increases throughput, and decreases costs.

The thirty nickel aluminide demonstration rolls were installed from 8 to 12 months ago. Inspection shows that the roll welds continued to maintain good integrity, the nickel aluminide roll bodies maintained their good high-temperature strength without sagging, and the roll surface showed no wear, only a light-green scale that thus far has no negative impact on roll performance or plate product. 


\section{INTRODUCTION}

\section{Project Background}

Bethlehem Steel (now ISG) had been proactive in its history of energy efficiency, and one aspect of that activity was partnering with others. Under the U.S. Department of Energy, Office of Industrial Technology's Emerging Technology Deployment Program, a partnership was developed with Bethlehem Steel and Oak Ridge National Laboratories to demonstrate a new nickel aluminide alloy technology related to energy efficiency, that when tied to other proven technologies, will result in an improved energy efficient furnace system, reduced environmental impact, and improved economic competitiveness.

The benefit of a demonstration at a large steel company is that steel is a large energy consumer, and any improvements will have a large impact within the steel industry along with other industries. Also, steel is an important material for most countries' economies. In the United States, there is a market for approximately 100 million tons of steel each year. It is produced in a number of shapes; with flat products - sheets and plates - being the most common. Much of the steel produced undergoes heat treatment in order to meet the final properties. A typical heat treatment for plates is austenitizing, where steel of ferritic structure [body centered cubic (bcc) crystal structure] is transformed to austenitic structure [face centered cubic (fcc) crystal structure] followed by cooling to achieve the desired properties. The steel plates used for bridges, buildings, and other components vary in size from 0.5 to 8 -in. thick by 84 -in. wide and up to 50-ft long. In a steel mill these plates are moved by transfer rolls in austenitizing (annealing) furnaces that operate at temperatures up to $1675^{\circ} \mathrm{F},\left(\sim 910^{\circ} \mathrm{C}\right)$.

The transfer roll alloy material in use today is an H-Series austenitic alloy that provides limited high-temperature strength, wear and oxidation resistance, but is the most cost effective material available. After a short service of two to three years in the annealing furnace the transfer rolls suffer from three major issues. First, the rolls tend to sag at the current operating temperatures $\left(1675^{\circ} \mathrm{F}\right)$, which also limits increased efficiency for operating at even higher processing temperatures. This sagging causes the rolls to become eccentric in their rotation, which produces a surface blemishing. Second, they blister, which causes additional blemishes on the plate surface moving over them, (Figure 1, (a) and (b)). Third, oxide from the steel plates being heat-treated may adhere to the roll surface. The oxide residue subsequently gets picked up by other steel plates going through the furnace, which again adds to the blemishing process. The roll blistering appears to be the most damaging phenomenon and is believed to occur from the impact of steel plates with the roll surface, which causes the local deformation of the roll surface. The roll-surface deformation from the plate impact appears related to low high-temperature strength of the H-Series alloys used for the current rolls. The roll distortion is also caused by the creep deformation of the roll body at the operating temperatures by either its own load or a combination of its own load and steel plates being transferred through the furnace. The roll pickup phenomenon may be caused by the reaction of iron oxide on the steel plate with chromium oxide that forms on the roll surface from its oxidation at operating temperature.

The surface blemishing of the plates results in downgrading of the product and minimization or elimination of surface-critical plate orders. The current furnace operating practice requires shutting down the furnace every one to three weeks so that the blisters can be hand-ground in-place inside the furnace to reduce the blisters, (Figure 1, (c) and (d)). These frequent shut downs result in energy losses, high operating costs for maintaining the rolls, and reduction of product throughput capability. 
Previous R\&D efforts at ORNL with nickel aluminide intermetallic alloy IC221M has shown the potential to solve this transfer roll and other high temperature furnace problems through its properties of high temperature tensile and creep strength, wear, and oxidation resistance. Also, formation of alumina as the surface oxide, which is less reactive with iron oxide on the steel plates as opposed to chromium oxide that forms on H-Series steels, should provide additional roll pickup resistance. In addition, the potential for competitive manufacturing costs makes this a very desirable material.

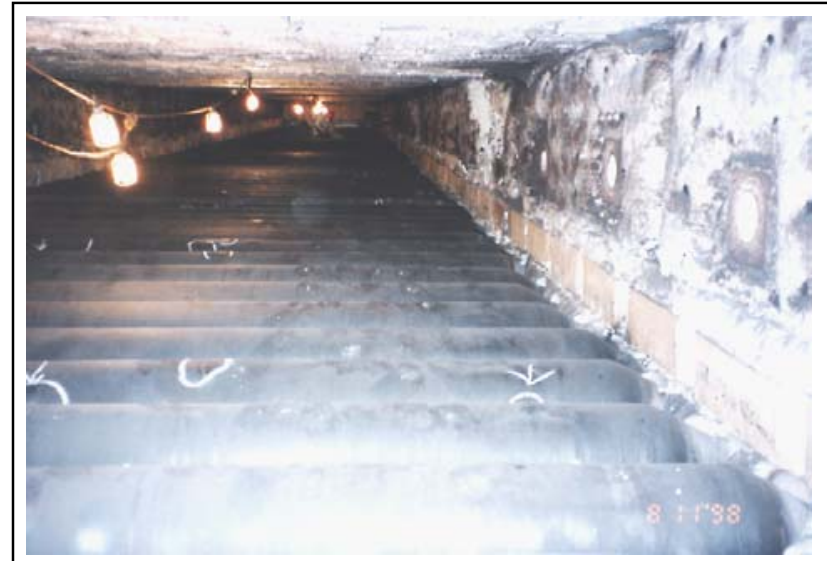

(a)

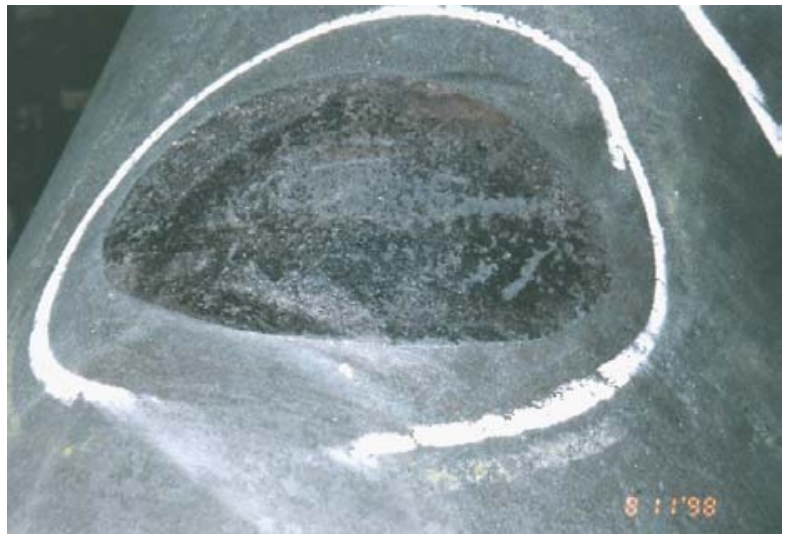

(c)

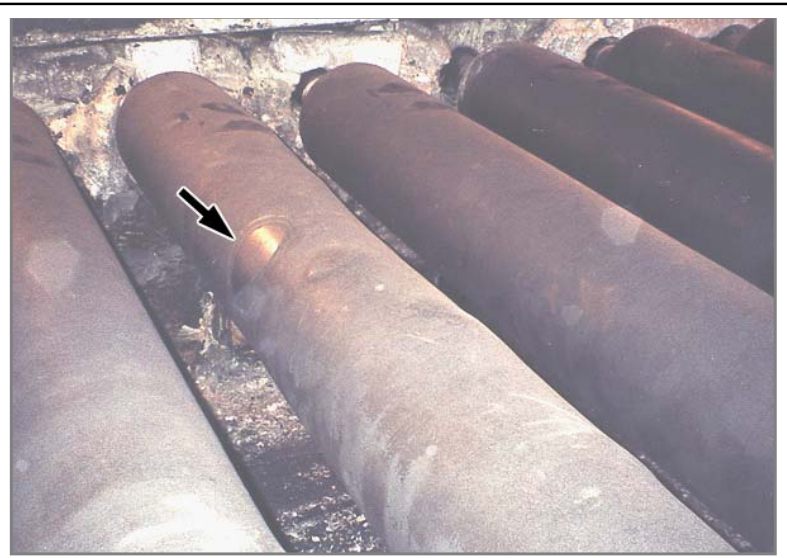

(b)

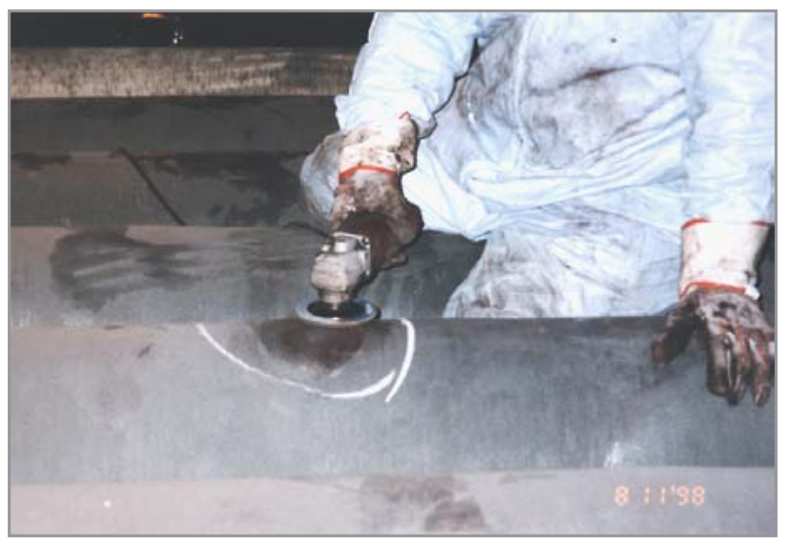

(d)

Figure 1. Photographs of conventional rolls in furnace: (a) furnace interior with 101 rolls, (b) general condition of rolls illustrating distortion, (c) detail of blister on roll surface, and (d) manual grinding of blister to blend with roll surface.

Preliminary testing of experimental nickel aluminide rolls of various composition, surface texture, and methods of joining to trunnions had taken place in Bethlehem's annealing furnace several years ago with reasonably good results. However, refinement of the joining process was required along with commercial manufacturing specifications, and several competitive vendors able and willing to produce the rolls. The partnership between the Department of Energy, Bethlehem Steel (now ISG), and Oak Ridge National Laboratory (ORNL) has reduced the risk to an acceptable level for all parties. While the overall goal of this project is to demonstrate energy and related efficiencies, most of the specific objectives are related to the demonstration of a large quantity of commercially produced nickel aluminide rolls. 
The three issues of high-temperature strength, blistering and oxidation resistance of the rolls will be evaluated along with the energy reduction developed when using this alloy.

\section{Nickel Aluminide Alloy Background}

The nickel aluminide-based alloy is a new class of alloy with an ordered crystal structure as opposed to most commercial alloys, which have disordered crystal structures, Figure 2. The ordered crystal structure of the nickel aluminide provides high creep strength from the reduced atomic diffusion rates and harder movement of dislocations. The ordered structure also results in yield strength that increases with temperature and peaks at approximately $1475^{\circ} \mathrm{F}$ to $1650^{\circ} \mathrm{F},\left(800\right.$ to $\left.900^{\circ} \mathrm{C}\right)$. The peak yield strength is approximately 30 to $40 \%$ higher than at room temperature. Since nickel aluminides also contain up to $12 \mathrm{wt} \% \mathrm{Al}$, they provide excellent oxidation resistance through the formation of $\alpha-\mathrm{Al}_{2} \mathrm{O}_{3}$ on the surface. The formation of $\alpha-$ $\mathrm{Al}_{2} \mathrm{O}_{3}$ also results in excellent resistance of $\mathrm{Ni}_{3} \mathrm{Al}$-based alloys to carburization and coking. The $\mathrm{Ni}_{3} \mathrm{Al}$-based ordered structure was known to be useful for a long time, however, its brittleness at both room and high temperatures prevented its development for commercial applications. The ORNL development of adding boron and controlling nickel-to-aluminum ratio resulted in nickel aluminide alloys that were ductile at room temperature. Further chemistry modifications to improve the intermediate temperature ductility and high-temperature oxidation have resulted in compositions that are useful for commercial applications. The composition most suitable for this project is IC-221M, which consists of the following composition:

$$
8.0 \% \mathrm{Al}, 7.7 \% \mathrm{Cr}, 1.43 \% \mathrm{Mo}, 1.7 \% \mathrm{Zr}, 0.008 \% \mathrm{~B}, 81.1 \% \mathrm{Ni}
$$

The nickel aluminide technology is patent protected in the United States and is licensed through ORNL to several producers for production in the United States. References 1 through 15 provide additional background information on this alloy, its properties, and its performance characteristics.
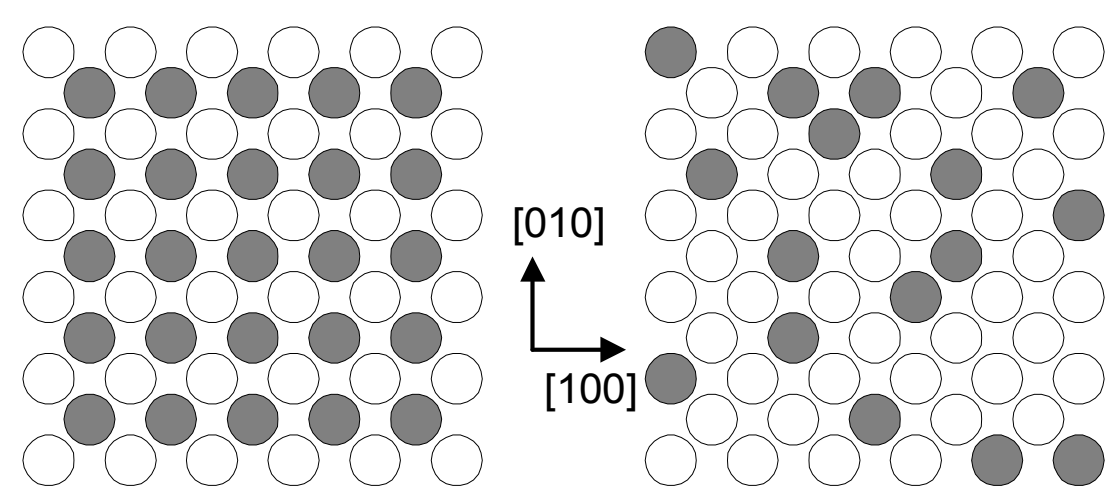

Figure 2. Schematic illustration comparing (left) ordered crystal structure of $\mathrm{Ni}_{3} \mathrm{Al}$ alloy with (right) disordered crystal structure of conventional alloy. 


\section{GOAL AND SPECIFIC OBJECTIVES}

The overall goal is to demonstrate and evaluate commercially produced nickel aluminide alloy rolls as part of an updated energy efficient large commercial annealing furnace system. These new nickel aluminide intermetallic alloy rolls, when tied to other proven technologies, should produce an improved energy efficient furnace system with reduced environmental impact and improved economic competitiveness.

Specific objectives related to the large-scale demonstration of the commercialization and capabilities of the nickel aluminide alloy were:

1. Prepare a project management plan to accomplish all the objectives in the one-year time frame.

2. Plan and install annealing furnace upgrades to enhance the demonstration's effectiveness.

3. Develop a commercial joining (welding) process.

4. Develop a commercial roll fabrication specification.

5. Select commercial roll suppliers, and have 30 demonstration nickel aluminide rolls fabricated for this project.

6. Provide roll fabrication quality control through field roll inspections and laboratory physical property tests of base metal and welds. Analyze data.

7. Install rolls in Bethlehem (ISG)'s plate hardening furnace.

8. Demonstrate roll performance for a minimum of two months.

9. Plan and implement various plate processing trials that will assist in evaluating alloy performance. Collect and analyze the operating data.

10. Complete the project demonstration within one year of initiation Complete final project report, including conclusions, recommendations, and summary.

\section{PROJECT MANAGEMENT AND ACTIVITY}

The project management approach of having key milestone dates for each of the objectives was utilized, see Table 1. With the extremely tight time schedule, work was begun when notification of award selection was received, months before the project paperwork was completed on June 17, 2002, the official project initiation date. June 16, 2003 is the project completion date and September 14, 2003 the final report and closeout paperwork due date.

The Bethlehem-ORNL team met in mid-March, 2002 and began work immediately on project objectives. The milestone dates were met - this was a challenge, not only because of the very short project time and technical challenges, but also because of the financial condition of Bethlehem Steel. Bethlehem was in bankruptcy when the project began, and the financial condition of Bethlehem and the steel industry as a whole continued to deteriorate with reductions in both manpower and financial resources. In April, 2003, Bethlehem was acquired by ISG, and it is a credit to ISG that the project activity continued its focus and hectic pace. 


\begin{tabular}{|l|l|l|l|l|l|}
\hline \multicolumn{7}{|c|}{ Table 1 - Milestone Status } \\
\hline \hline \multicolumn{7}{|l|}{} \\
\hline \hline Objective & Description & Aim-Begin & Aim-End & Actual-Begin & Actual-End \\
\hline 1 & Milestones & $3 / 15 / 02$ & $3 / 30 / 02$ & $3 / 15 / 02$ & $3 / 22 / 02$ \\
\hline 2 & Furnace Improvement & & & & \\
\hline A & Flame Safety & $3 / 15 / 02$ & $1 / 1 / 03$ & $3 / 15 / 02$ & $1 / 1 / 03$ \\
\hline B & Dampers & $3 / 15 / 02$ & $2 / 1 / 03$ & $3 / 15 / 02$ & $2 / 15 / 03$ \\
\hline C & AC Motor Drives & $3 / 15 / 02$ & $1 / 1 / 03$ & $3 / 15 / 02$ & $3 / 15 / 03$ \\
\hline 3 & Weld Process & $3 / 15 / 02$ & $5 / 1 / 02$ & $3 / 15 / 02$ & $5 / 1 / 02$ \\
\hline 4 & Specification & $3 / 15 / 02$ & $6 / 1 / 02$ & $3 / 15 / 02$ & $6 / 1 / 02$ \\
\hline 5 & Suppliers & & & & \\
\hline A & RFP & $3 / 15 / 02$ & $6 / 1 / 02$ & $3 / 15 / 02$ & $6 / 1 / 02$ \\
\hline B & Ship Rolls & $8 / 1 / 02$ & $9 / 30 / 02$ & $8 / 1 / 02$ & $12 / 20 / 02$ \\
\hline 6 & Quality & & & & \\
\hline A & Field Inspection & $8 / 1 / 02$ & $9 / 30 / 02$ & $7 / 28 / 02$ & $12 / 18 / 02$ \\
\hline B & Lab Tests & $8 / 15 / 02$ & $10 / 31 / 02$ & $9 / 1 / 02$ & $6 / 16 / 03$ \\
\hline 7 & Install Rolls & $9 / 30 / 02$ & $12 / 20 / 02$ & $8 / 7 / 02$ & $1 / 5 / 03$ \\
\hline 8 & Roll Demonstration & $4 / 15 / 03$ & $6 / 15 / 03$ & $2 / 18 / 03$ & $6 / 16 / 03$ \\
\hline 9 & Furnace Trials & $4 / 15 / 03$ & $6 / 15 / 03$ & $2 / 18 / 03$ & $6 / 16 / 03$ \\
\hline 10 & Report & & & & \\
\hline A & Analyze Data & $5 / 15 / 03$ & $8 / 16 / 03$ & $3 / 15 / 03$ & $8 / 15 / 03$ \\
\hline B & Complete Report & & $9 / 1 / 03$ & & $9 / 1 / 03$ \\
\hline
\end{tabular}

\section{FURNACE MODIFICATIONS AND IMPROVEMENTS}

\section{Updated Furnace Flame Safety Controls}

In order to insure repeatable and safe furnace operation it was deemed important to upgrade the flame safety control equipment on this furnace. In the weekly light up process, the steps of heating from a relatively cool furnace to operating temperatures near $1675^{\circ} \mathrm{F}$ are hazardous in that if the flame is extinguished in the initial steps of heating, while the temperature is below the self-ignition point, the furnace can fill with gas and explode. That did occur at this furnace in the not too distant past, and so it is important that state of the art safety equipment be installed, primarily for the safety of personnel, but also to protect the equipment and this investment from catastrophic damage. It also provides a smoother, more repeatable furnace heat-up by insuring that all burners and all zones are heating at the prescribed heating rate.

There are 132 burners on this furnace. Every pilot for each burner was changed to a new design that provided a longer flame. New flame detectors, UV, to replace the older flame rods were also added to each burner. New igniters were added to the system, two per zone for each of the 10 zones. At the furnace, a new computer screen allows the operator to monitor data in each zone and was added to simplify startup and adjustments. In addition, a new purge panel was included. All of these new components were tied together with a large quantity of wiring and conduit, see the picture of the annealing furnace, Figure 3

The equipment is working well. 


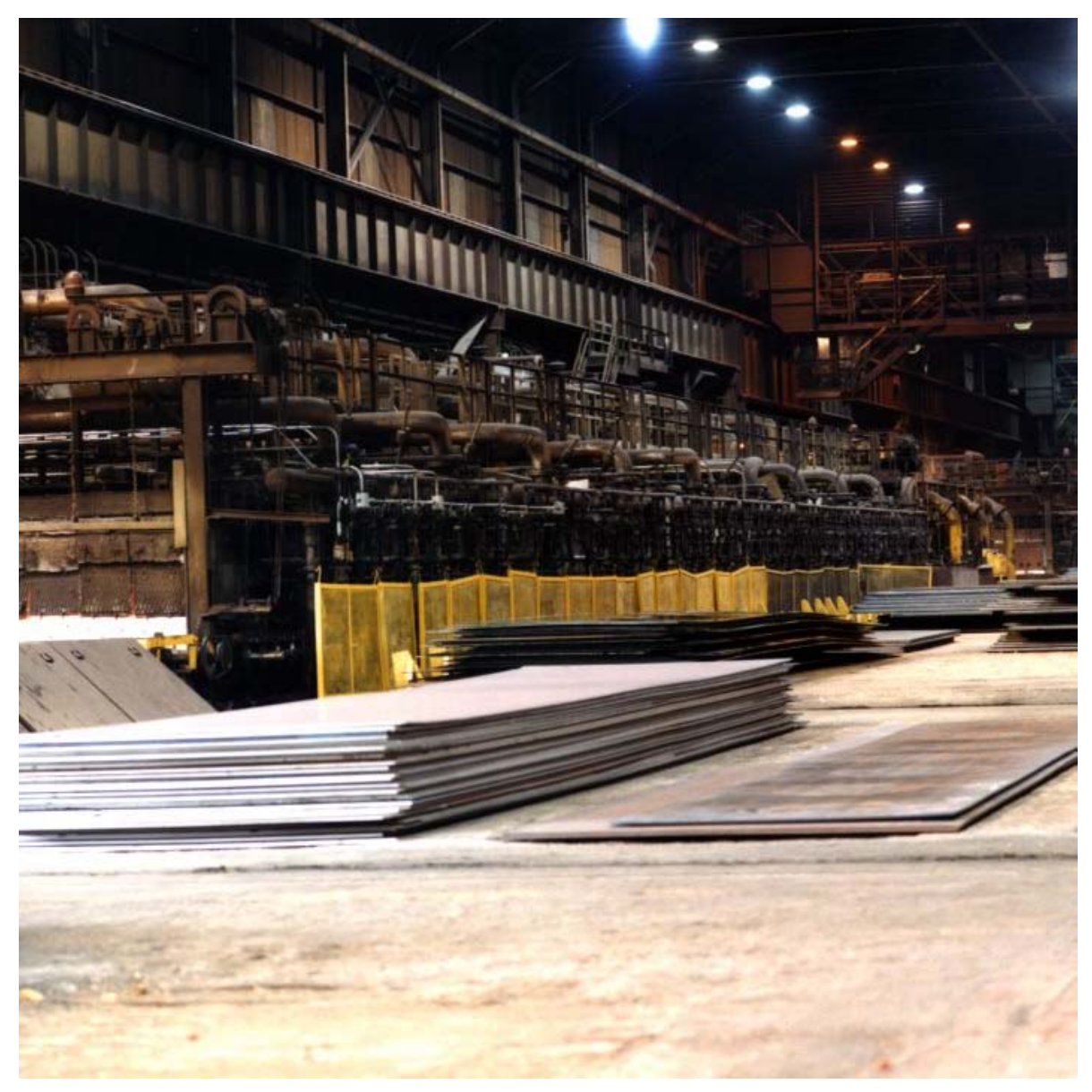

Figure 3. Overall View of Burns Harbor Plate Annealing Furnace

\section{Improved Dampers and Controls}

Pressure control in a furnace is extremely important to both heating quality and energy efficiency. Twenty five dampers are part of the furnace, 13 on one side and 12 on the other side. These were originally fixed pressure control plate types that were designed to provide pressure control at the most common firing rate in each zone. They provided a benefit, but were difficult to reset accurately and easily, and did not provide good pressure control at all burner turn-down ratios.

With the evaluation of the nickel aluminide rolls as part of an energy efficiency demonstration, it was timely to upgrade the pressure control equipment to improve the heating uniformity and energy efficiency at all burner turn-down ratios. This upgrade of furnace dampers provides an overall heating system that will allow not only more efficient heating, but insure a more uniform heating of plate product in the annealing furnace.

Equipment was procured from Bloom Engineering Co and installed by ISG Burns Harbor Plate maintenance personnel. The damper control principle is based on a weighted arm that provides a 
preset damper pressure control at all burner operating levels. The new equipment is also designed with slotted-arm counter weights for ease of adjustment during operation and the periodic calibration of the pressure control system. The new equipment was installed immediately after the project's baseline data collection had been completed.

This equipment after initial adjustments is working extremely well.

\section{AC Roll Motor Drives}

This was not officially part of the demonstration project, but once Bethlehem management became aware of this equipment's impact for taking advantage of the benefits of the nickel aluminide rolls, the new drive system was included by Bethlehem. The past method of driving the rolls was with 15 DC motors. The rolls moved the plates through the furnace at a speed that would minimize plate surface abrasion from the blistered and sagging rolls; however, this speed was too fast for proper heating with one pass straight through the furnace, so all plates required reversal or oscillation to provide proper dwell times in the various heating zones. This created problems in that additional plate abrasion occurred during this oscillation, and hearth coverage was not at optimum levels. With the anticipation of higher strength nickel aluminide rolls that would not sag or blister, the addition of AC motor drives to provide improved motor control, particularly at lower speeds, and much less maintenance, was included.

The new motor drive design included seven Allen-Bradley $1336 \mathrm{AC}$ drives to replace the fifteen original DC motors. The new system also eliminated the clutch and drive chains. The ability to be at full torque at zero speed and have good control at low speeds was a large and overriding benefit to plate processing. This new drive system has much more flexibility than the older system. The benefits provided by these new drives are the ability to operate at slow speeds that allows straight-through processing which results in higher quality plate product, also, greater hearth coverage which yields improved energy efficiency and increased productivity.

This equipment is working well and is going through the adjustment and fine-tuning phase that will maximize its performance.

\section{JOINING (WELD) PROCESS DEVELOPMENT}

A substantial effort was directed toward the development of welding filler metals and welding procedures as part of the development activities at ORNL. Three welding filler metals were developed in the initial stages of the work, and availability of the filler metals in commercially viable forms and quantities were establish through interactions with Stoody Company (Bowling Green, KY). The three filler metal compositions are shown in Table 2. The IC $221 \mathrm{~W}$ composition was developed primarily for cosmetic repairs to castings, welding IC $221 \mathrm{M}$ to itself, and welding overlay applications. The IC221W composition has the best compatibility with IC221M in terms of chemical composition and mechanical properties. The IC221LA composition was developed to retain the environmental resistance properties of IC221M but at slightly lower strength levels. The lower strength of IC221LA is accompanied by higher ductility, and this makes IC2221LA more resistant to cracking in the high-mechanical-restraint conditions often encountered during welding. The NiCrZr filler metal composition was developed primarily to maintain good oxidation resistance with very high ductility. The intention was to use this alloy for difficult welding situations where the lower ductilities of the high strength alloys made cracking virtually unavoidable. 
Table 2 Nominal compositions of welding filler metal alloys for IC221M nickel aluminide

\begin{tabular}{|c|c|c|c|c|c|c|}
\hline ID & $\mathbf{N i}$ & Al & $\mathbf{C r}$ & Mo & $\mathbf{Z r}$ & B \\
\hline IC221W & Balance & 8 & 7.7 & 1.4 & 3.0 & 0.003 \\
\hline IC221LA & Balance & 4.5 & 16 & 1.2 & 1.5 & 0.003 \\
\hline $\mathrm{NiCrZr}$ & Balance & --- & 20 & --- & 1.5 & 0.003 \\
\hline
\end{tabular}

Once filler metal compositions were established for welding IC221M, efforts to develop welding procedures were intensified. Nearly all of the initial development work done for established general weldability properties of IC221M and for establishing compositions for welding filler metals was done using the manual gas tungsten arc (GTA, commonly referred to as TIG) process. There were important reasons for relying on manual GTA welding for the initial work. GTA welding typically produces weld deposits of the highest quality with excellent retention of filler metal chemical composition characteristics. The process also has good flexibility for controlling the amount of heat used for making welds. This feature is especially important for welding most high strength nickel-based alloys because they typically have higher sensitivity to welding heat input properties than steels, for instance. Also, GTA welding can be done either with no filler metal additions (i.e., autogenously) or with very modest filler metal requirements. When only small quantities of filler metal are available, as during development activities, GTA welding is highly desirable. Disadvantages of GTA welding are that it deposits filler metal at lower rates and it requires operators of higher skill than competing processes.

All of the initial welded experimental test rolls of IC221M that were installed in the 160" plate mill furnace at ISG Burns Harbor were manually welded by the GTA process. There were important reasons for using this approach. Perhaps most important was that this was the welding process with the greatest experience base in terms of application to parts and properties of welds. Also, during this period of development rolls were being produced in small lots, often one at a time. During this time, the performance of the alloys and the welded construction were more important concerns than issues related to large-scale manufacturing. Consequently, development of welding procedure for large-scale manufacturing situations was recognized as being important, but viewed as a secondary concern.

There were two important conclusions drawn from evaluation of these test rolls that directly influenced additional welding development. One was that using trunnions of conventional cast stainless steel alloys such as HK would make the nickel aluminide roll assemblies more competitive with traditional all-stainless-steel rolls. The second was that manual GTA welding would need to be replaced with automated processing to achieve consistent weld quality and improve manufacturing costs. The desire to use HK rather than IC221M trunnions dictated consideration of dissimilar metal welding. The needs to improve both consistency of weld quality and manufacturing costs meant that procedures for either automated GTA welding or gas metal arc (GMA, or MIG) welding would require development.

As was done in the initial welding development activities, manual GTA welding was relied upon to develop procedures for welding IC221M to HK cast stainless steel. This work established that the most consistent way to obtain crack-free welds was to use combinations of the IC221LA and NiCrZr filler metals. Mechanical testing showed that the strength of the IC221LA filler metal alloys was intermediate to those of IC221M and HK, and that IC221M-to- 
HK welds made with IC221LA filler metal always failed in the HK. Welding on rings cut from centrifugally cast tubes of IC221LA and HK indicated that using the NiCrZr filler metal for the first few layers of weld deposit significantly improved the probability of controlling and avoiding cracking. As a result of these activities it was decided that the preferred approach for welding IC221M to HK was to use $\mathrm{NiCrZr}$ filler metal for root passes and several additional layers of weld deposit up to about $1 / 4$ of the total weld deposit thickness. Welds would be completed from that point using the IC221LA filler metal.

From this point, emphasis was placed on developing welding procedures using either the GMA welding process or the automated GTA welding process. The GMA process was given the higher priority because it is capable of higher weld filler metal deposition rates and therefore higher productivity. Test welds were made using both 1.1-mm-diameter wire and 1.6-mmdiameter wire. Also, a large number of shielding gases were evaluated in order to control the flow of the deposited weld metal and weld bead contours. The preferred materials for making the GMA welds were 1.1-mm-diameter wire and a shielding gas of $50 \% \mathrm{Ar}-50 \% \mathrm{He}$. Several trial GMA welds were then made using 14 inch $(355-\mathrm{mm})$ diameter centrifugally cast rings of IC221M and HK. A photograph of one of the test welds mounted on a positioner is given in Figure 4. The edges of the rings were machined to the configuration shown in the Welding Procedure section of the roll purchase specification given in Appendix A. Initial trials indicated that the IC221LA filler metal produced better weld bead contours on the $\mathrm{HK}$ than the $\mathrm{NiCrZr}$ filler metal. Consequently the IC221LA was used to complete the entire test weld. The welding on the test rings was done by automatically rotating the assembled rings to produce a welding speed of $7.5 \mathrm{ipm}(3 \mathrm{~mm} / \mathrm{s})$ while holding the GMA welding torch stationary in a fixture at the apex of the joint. A typical test weld was completed with 5 beads of filler metal deposited under

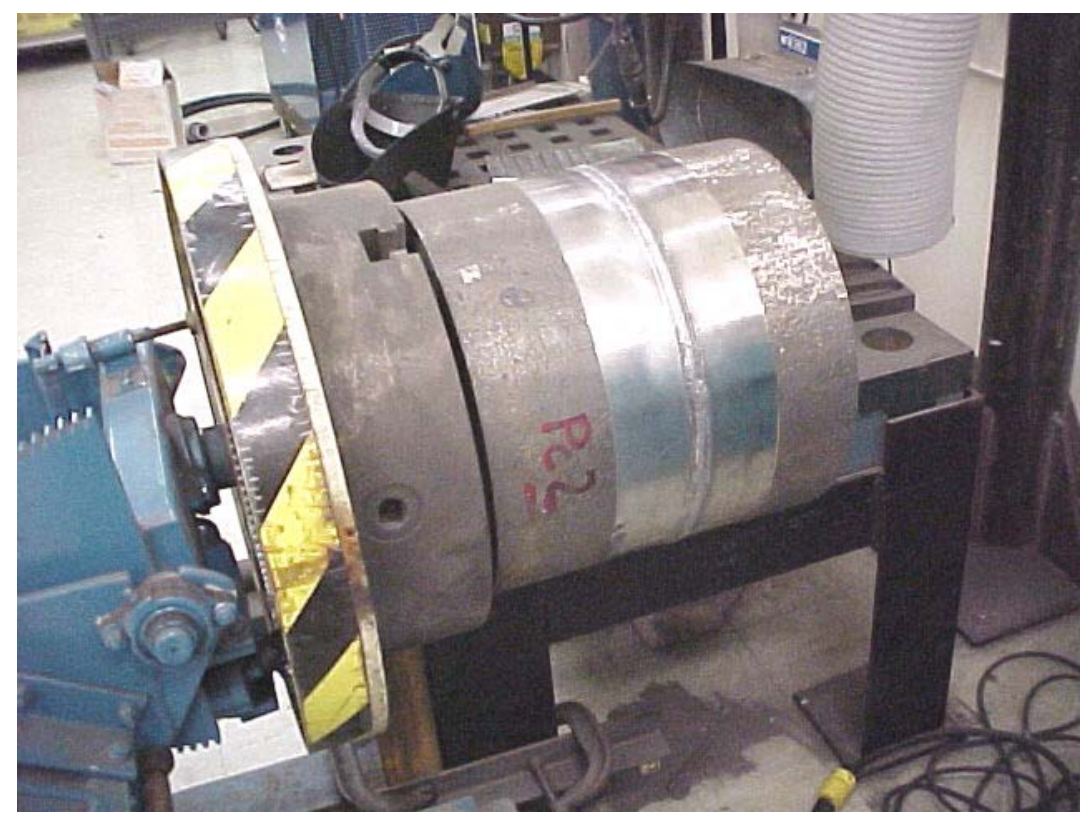

Figure 4. Set-up that was used for GMA welding of centrifugally cast rings of IC221M to HK. Completed weld is shown. 


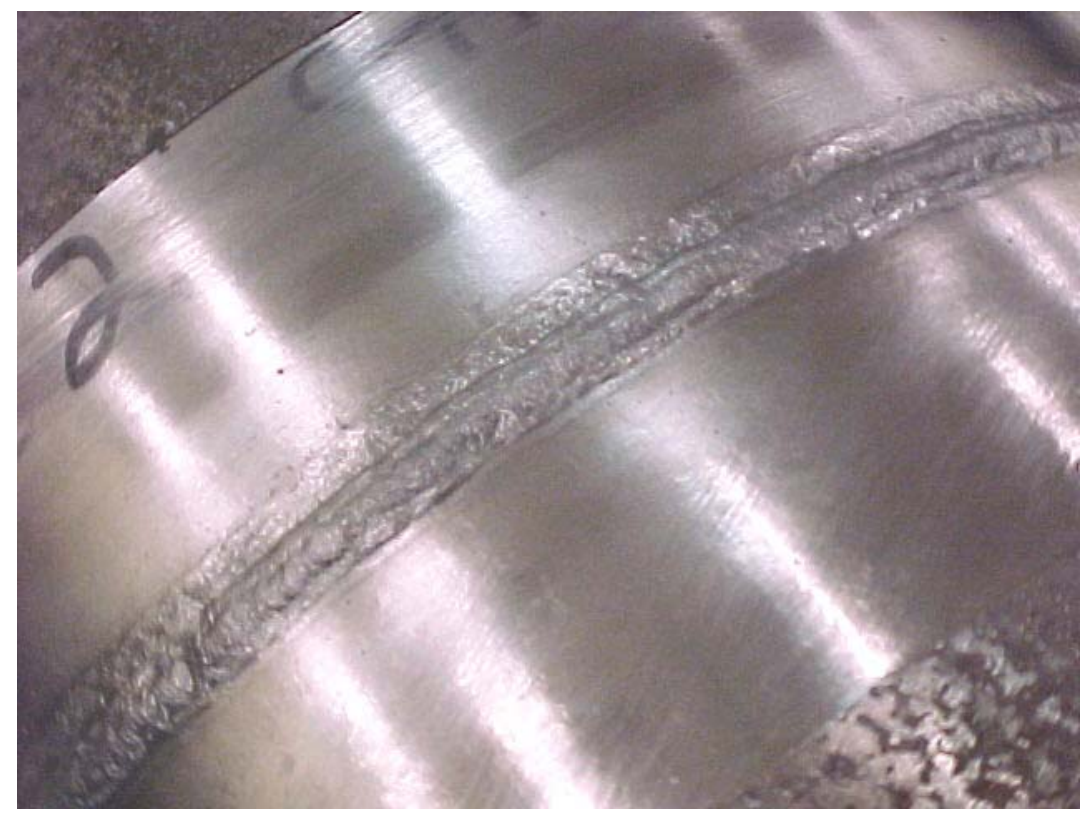

Figure 5. Surface appearance of completed GMA weld of centrifugally cast rings of IC221M to HK.

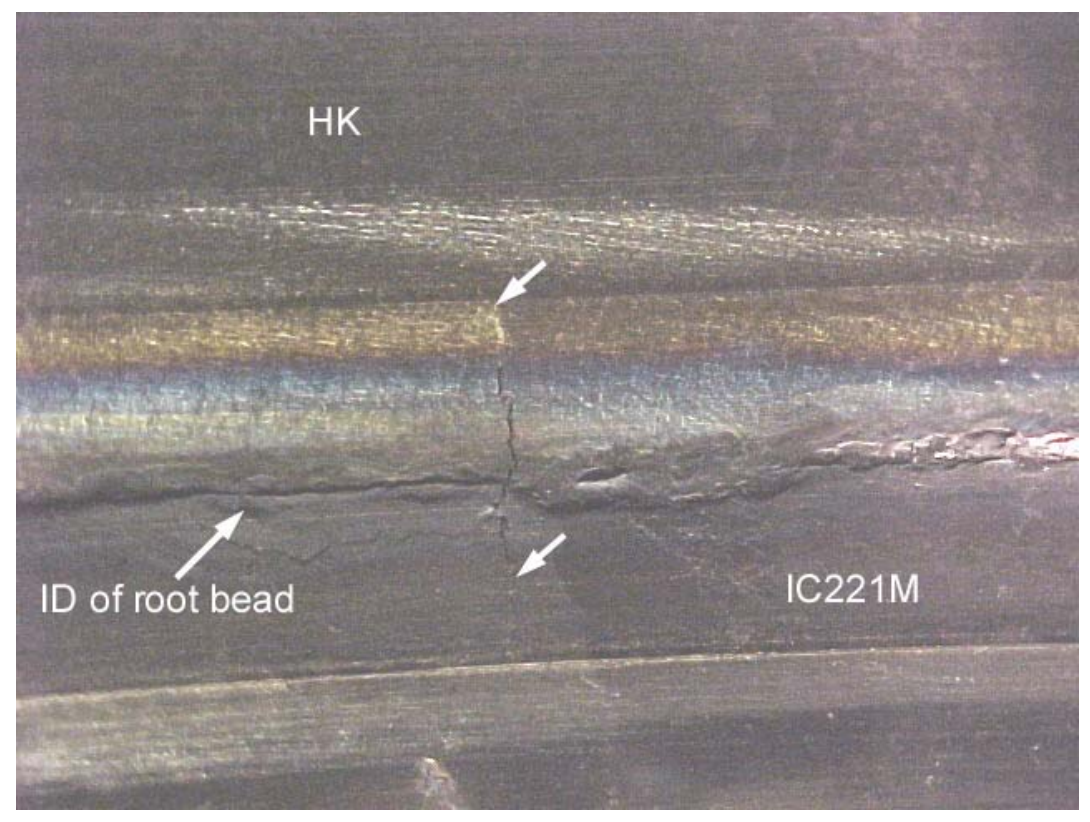

Figure 6. Example of cracks that extended perpendicular to the welding direction on the ID surface of the GMA weld. The crack is many times longer than the width of the weld bead at this location. Backing ring has been removed. 


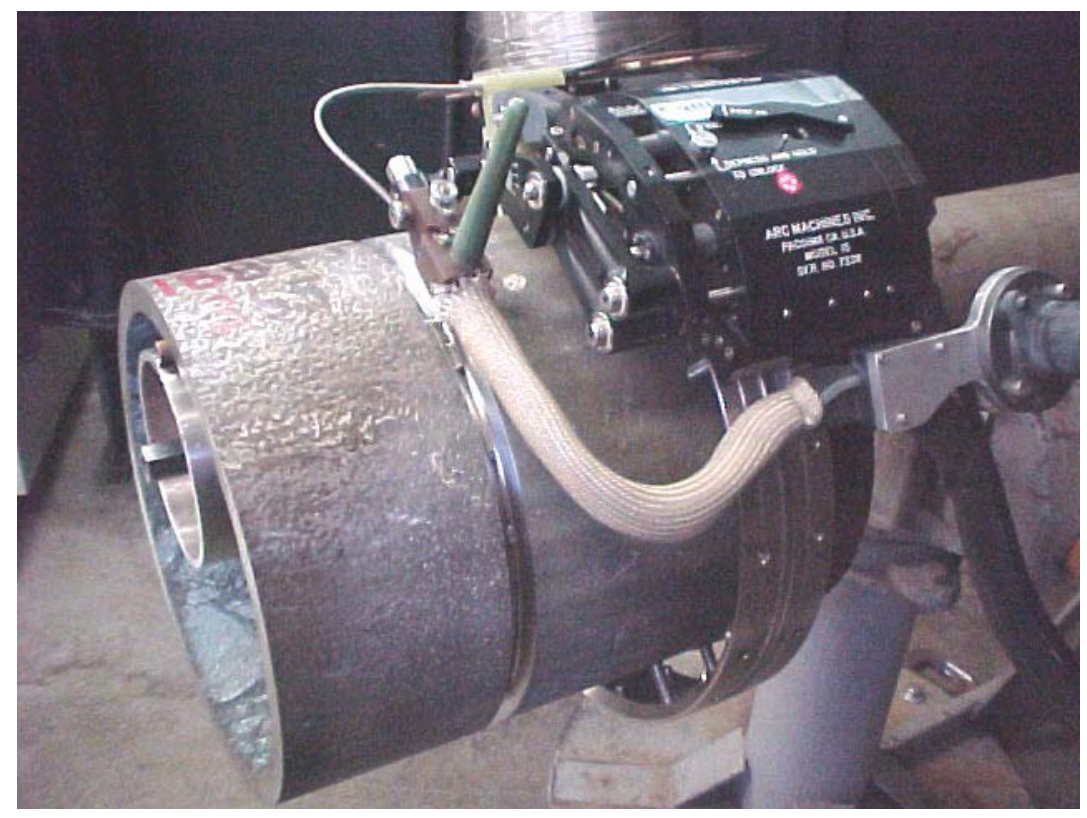

Figure 7. Detail of Arc Machine set-up for automatic GTA welding of IC221M-HK roll sections.

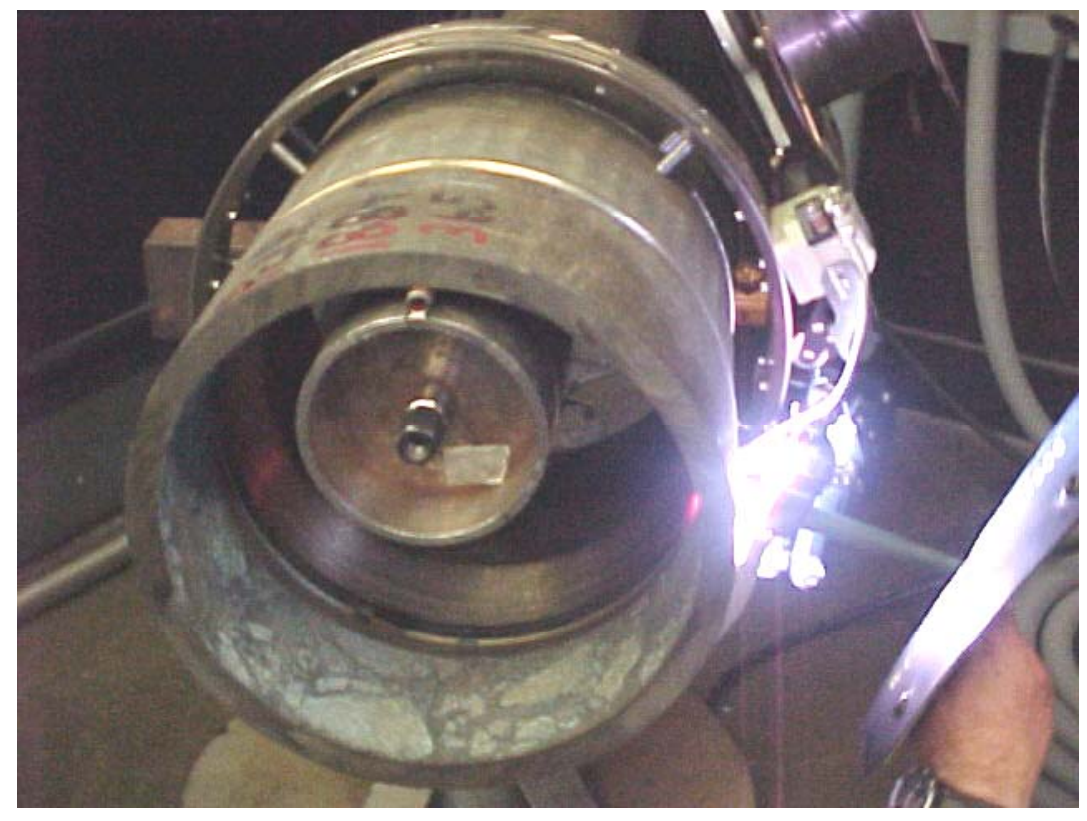

Figure 8. Root pass being deposited by automatic GTA welding. 


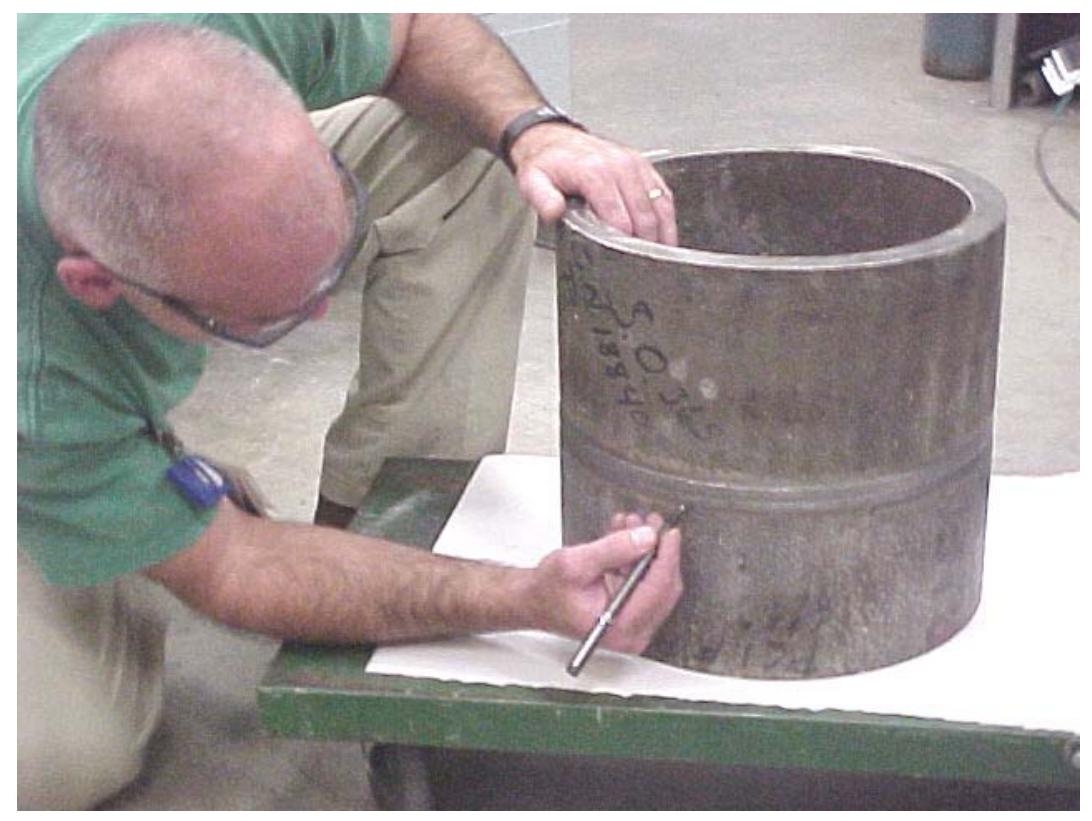

Figure 9. Completed automatic GTA weld being inspected prior to radiography.

an 'arc-on' time of 30 minutes. Some problems were experienced on the root passes that required repairs before proceeding. Otherwise the welding was straightforward. Light grinding was used following each weld bead to prevent excessive build-up of surface oxides due to the relatively high Al content of the filler metal alloy. The visual appearance of the welds was excellent as illustrated in Figure 5. Radiographs of the GMA welds indicated that they contained some scattered porosity, but at acceptable levels for this welding process and type of material. However, the GMA weld also contained some large cracks that were also visible on the ID surface as shown in Figure 6. These large cracks extended across the weld into the base metals. The nature of the cracks suggested that they were caused by the unique way that stresses accumulate during GMA welding, and the relative inability of both the IC221M and the HK base metals to accommodate the strains associated with the welding induced stresses.

The equipment used to develop a procedure for the automated GTA welding consisted of a track that was first mounted to the centrifugally cast rings. A GTA welding head including mechanism for feeding welding wire was then positioned on the track. In this case, the rings were stationary and the welding head moved, going from the flat, vertical down, overhead, and vertical up orientations as it tracked around the assembled rings. The set-up used for GTA procedure development is shown in Figure 7. The GTA welding used argon shielding gas with the 1.1-mm-diameter welding wire. The welding parameter sheets used to make the pictured weld are provided in Appendix B. Figure 8 shows the progress during deposition of the root pass. The groove was filled with 10 passes that amounted to an 'arc-on' time of 82 minutes. Welding was stopped after each bead for visual inspection and minor adjustments to the equipment. Also, some light grinding was done between passes to remove surface oxides from the weld beads. The visual appearance of the weld was excellent. The entire weld was radiographed and there was no sign of cracking. Figure 9 shows the completed weld being visually inspected prior to radiography. 
This procedure formed the basis for the welding procedure recommended for making the HP trunnion-to-IC221M roll body welds for the large-scale evaluation, Appendix A. Staff from ORNL closely monitored welding of the production rolls. They made a number of visits to the manufacturers' sites to assist with transfer of the welding procedures and training of welders.

\section{ROLL SPECIFICATION DEVELOPMENT}

The commercial roll specifications were developed through discussions with suppliers and a review of the roll casting steps at the supplier's facilities, along with the selection of laboratory tests for proper alloy chemistry, physical properties, and welds. Added to this were end-user processing requirements such as finish of the roll body surface, material type for trunnions, etc. The specifications include: (1) background; (2) roll design and assembly; (3) chemical analysis requirements; (4) melting process; (5) casting surface finish; (6) cutting and machining; (7) trunnions; (8) welding; (9) test data - which included: (a) data for each roll, (b) welder qualification, and (c) tensile data ; (10) special notes; (11) roll balancing; (12) markings; (13) inspection; (14) quality assurance requirements; (15) shipment; (16) qualification of roll manufacturer; (17) acceptance criteria for rolls; (18) casting and roll fabrication records; and (19) procedures for gas tungsten welding of nickel aluminide alloy IC-221M to H-Series cast austenitic alloy - including details of: (a) base metal, (b) filler metal, (c) joint and groove preparation, (d) weld joint assembly, (e) welding position, (f) welding process and equipment, (g) preheat and interpass temperatures, (h) welding of joint, (i) cleaning of weld beads, (j) peening, (k) defects, (l) post-weld heat treatment, (m) acceptance criteria for dye-penetrant examination, (n) repair procedures, and (o) joint design.

Revisions were made to the specifications as roll manufacturing proceeded and questions arose. Revision 8, made November 21, 2002 is the latest version of the Nickel Aluminide Cast Roll Specifications. The complete specification is listed in Appendix A.

The specifications successfully guided the suppliers through a commercial fabrication of the nickel aluminide alloy rolls, and can be used as a guide in the fabrication of a wider range of nickel aluminide components.

\section{ROLL PROCUREMENT AND FABRICATION}

\section{Supplier Selection Process}

The selection of commercial roll suppliers capable of producing a quantity of nickel aluminide rolls with the desired quality, a competitive price, and a delivery time that would fit the tight time frame of the project, was a concern. The Bethlehem team, having the most experience with cast roll suppliers, utilized their Purchasing Department roll specialists combined with their Operating and Maintenance personnel to develop a roll supplier list. This list was selective in that it only included companies who possessed the capability for high quality large cast rolls. From this list, four suppliers were selected that had capabilities of working with new alloys and developments, were geographically located to be able to service the Burns Harbor plant, and were interested in participating in this project. Contact was made with the four suppliers and visits made to several of them while the RFP (Request For Price quotation) was being developed. 
Thirty rolls were part of this project's demonstration, but it was noted in earlier developmental trials that the balance of the rolls in the furnace obscured the effect of the experimental rolls on the plate product. Therefore, neutral background rolls were required that would not interfere with the demonstration. Similar nickel aluminide rolls were the best solution, so additional nickel aluminide rolls to fill the furnace, not part of this demonstration project, were procured at the same time as the project rolls and subjected to the same quality and delivery time requirements

The RFP was developed by the Bethlehem-ORNL team, and administered through the ORNL Purchasing Department. The nickel aluminide roll specification was the major component of the RFP.

RFPs were sent to the four selected suppliers. The top two suppliers who showed a strong willingness and capability to produce the rolls in the given timeframe and at a cost effective price were selected. Duraloy, Inc., Scottdale, PA, had prior experience in producing various nickel aluminide components, and Ultra-Cast, Inc., Peru, IN, had experience with high quality refinery equipment and welds, and were located close to Burns Harbor.

Prices for these demonstration rolls were competitive compared to the existing rolls, approximately $20 \%$ to $30 \%$ above the price of the existing rolls. Prices would be expected to go lower as utilization of the new alloy increases.

\section{Roll Fabrication}

The key roll fabrication process steps entail the casting of nickel aluminide roll bodies, casting of H-Series stainless steel trunnions, welding of these stainless steel trunnions to the nickel aluminide roll body, welding of the wrought stainless steel bearing shaft to the trunnion, balancing the rolls, inspection by an ORNL representative trained in field testing and evaluation of product at the supplier's site., and shipping of the rolls.

The nickel aluminide alloy IC-221M was melted in air-induction-melting furnaces using the furnace-loading scheme developed by ORNL. In the initial melts, the melt stock was all virgin; however, as the manufacturing progressed, the ends from the roll bodies were mixed with the virgin stock. The molten metal was centrifugally cast into roll bodies of $14 \mathrm{in}$. OD $\times 12 \mathrm{in}$. ID $\times 164$ in. long $(356 \mathrm{~mm} \times 305 \mathrm{~mm} \times 4166 \mathrm{~mm})$. The roll bodies, just removed from the mold and undergoing the cooling process, are shown in Figure 10 (a). After cooling, rings were cut from the hot (pouring end) and cold ends of the roll body for testing.

The H-Series stainless steel alloy, (Fe-36.7Ni-26.7Cr-1.53Si-1.75W-0.46C), was also melted in AIM furnaces and sand-cast into trunnions.

Roll bodies were then cut to the correct length and ends prepared for the welding process with the desired bevel design. No unusual problems were encountered during cutting and machining the bevels in the nickel aluminide roll body. The H-Series trunnions were also machined to get the proper bevel on the end. The roll body and the trunnion were assembled and prepared for welding. The welding step used two commercially prepared filler wires, one for the root pass and the other for filling the weld. The welding process was gas tungsten arc with root pass being the manual step and the remainder of the passes being automatic welds. Argon was used as the cover gas for all welds. Figure 10 (b) shows roll bodies being readied for welding, Figure 10 (c) shows examples of welded trunnions to roll bodies, Figure 10 (d) shows a close-up of a completed weld, Figure 10 (e) shows a magnified view of the weld, Figure 10 (f) shows one end of several completed rolls, Figure 10 (g) shows several completed rolls ready for shipment, and Figure $10(\mathrm{~h})$ shows rolls at the mill ready for installation. 


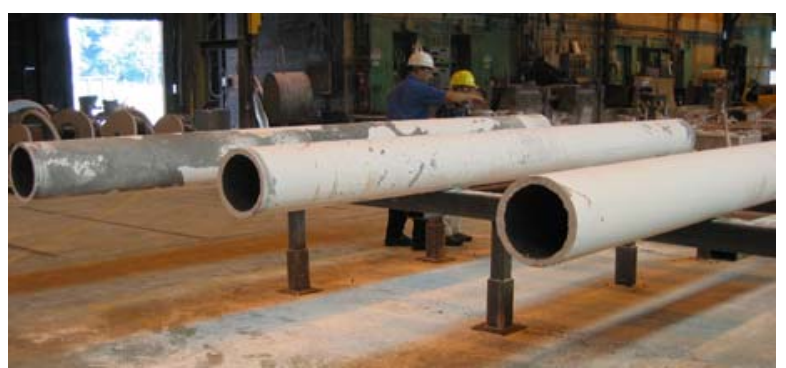

(a)

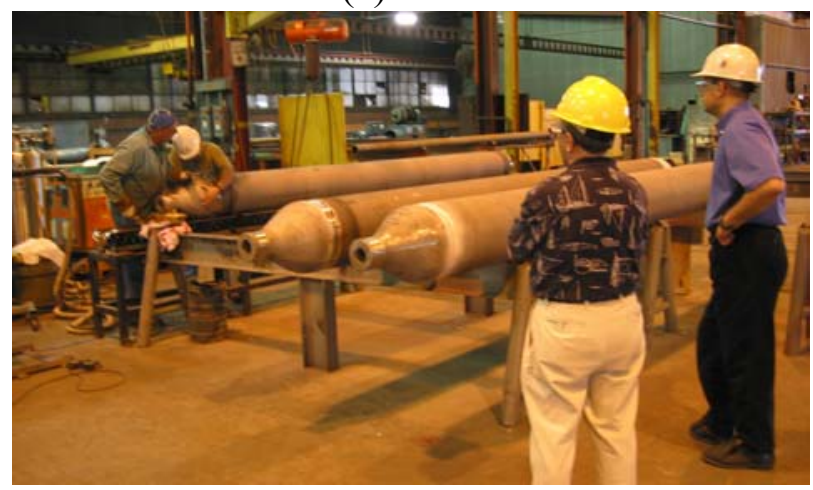

(c)

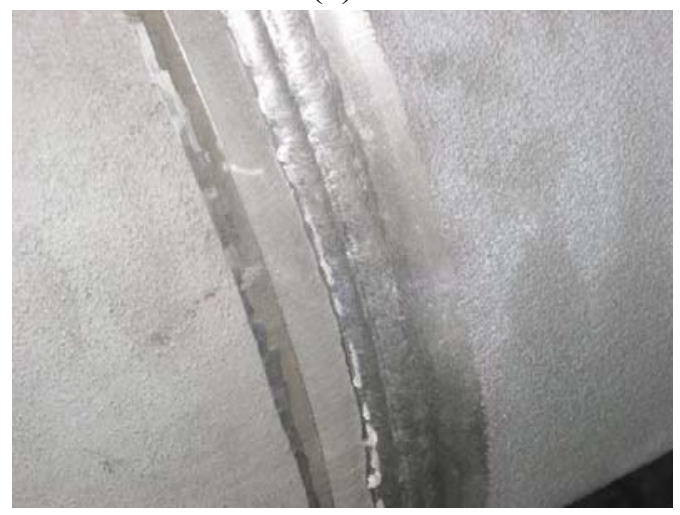

(e)

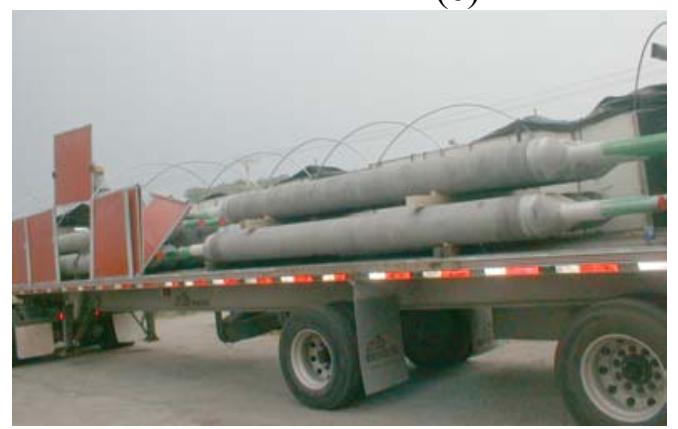

(f)

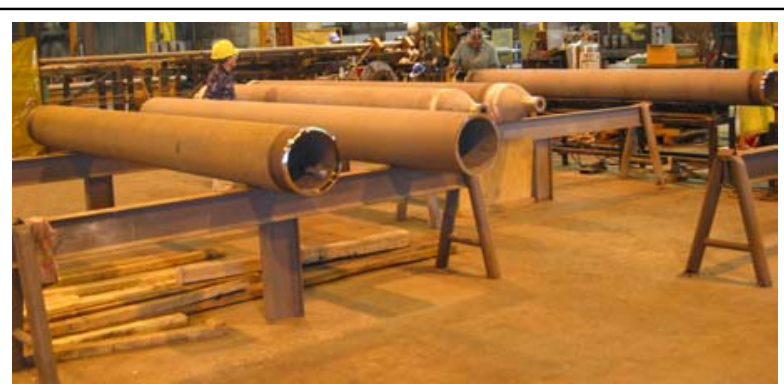

(b)

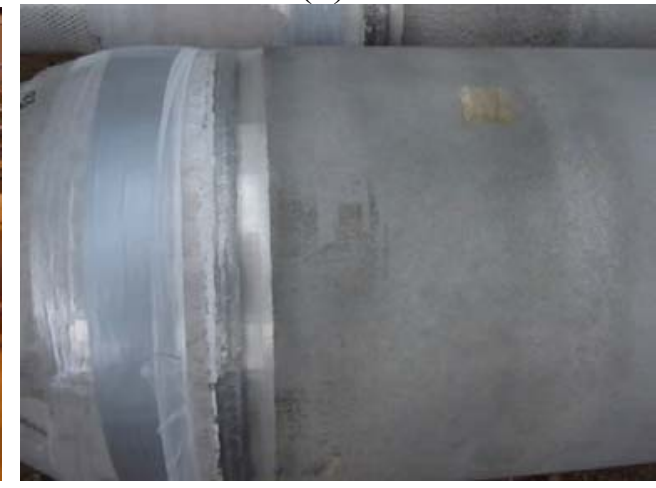

(d)

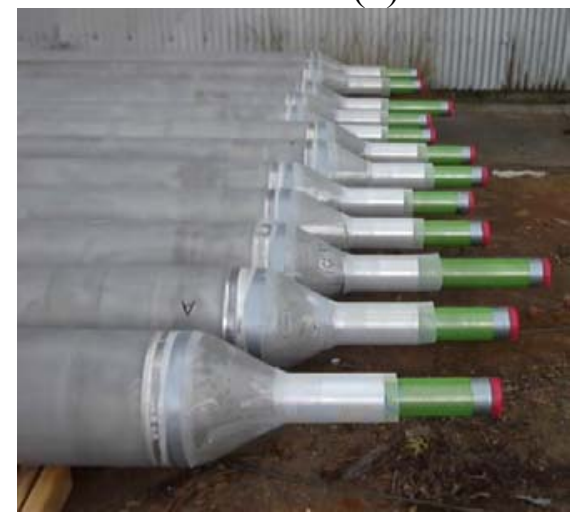

(f)

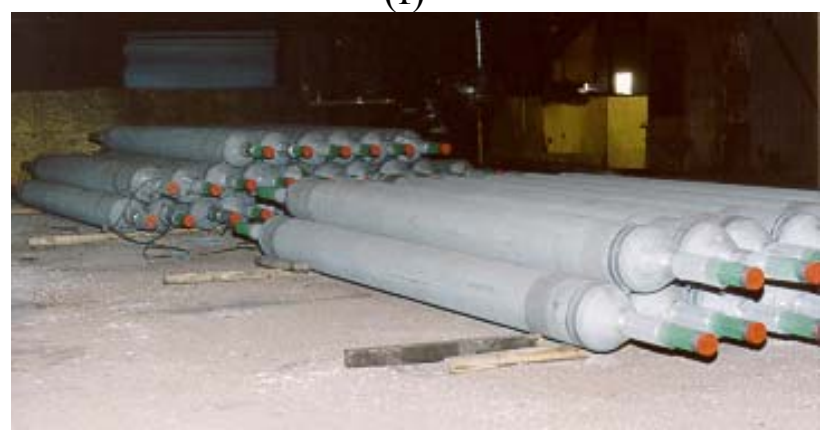

(g)

Figure 10: Various steps in the manufacturing of nickel aluminide rolls: $(a)$ cast bodies, $(b)$ machined ends and ready to weld, $(c)$ welded trunnion to roll body, $(d)$ weld close-up, $(e)$ magnified view of the weld, $(f)$ completed rolls, $(g)$ ready for shipment, and $(h)$ ready for installation. 


\section{ROLL QUALITY CONTROL}

\section{Field Inspection Before Roll Shipment}

Each nickel aluminide roll was inspected by an ORNL procurement quality control specialist. Roll shipment was not allowed until all the required documentation of each roll as requested in the specification was received. In addition, the inspector checked each roll at the supplier's site.

The acceptance criteria are summarized as follows:

1. Chemical Analysis: Chemical analysis of each roll must be within the specified range for IC$221 \mathrm{M}$ for the roll body, (see Table 1 in the specification), and HP-modified and Type 309 stainless steel for the trunnion.

2. Dimensional Control: All dimensions must meet the requirements specified in the approved (Bethlehem Steel) roll drawings.

3. Surface Finish: Rolls will be used in the as-cast condition and its surface finish must be 560 rms or better (smoother) as determined using a C-9 Cast Microfinish Comparator available from GAR Electroforming of Danbury, CT.

4. Weld Quality: Weld inspection report for each roll must show that the assembly welds conform to the acceptance criteria detailed in the attached weld procedure. The weld wire chemistry certifications must be provided for each weld.

5. Marking: Markings that uniquely identify each roll assembly must be clearly visible on the shaft end of each roll.

6. Documentation: All required documentation and inspection reports (as listed in the specification) shall be signed in blue or black ink by the person completing the work, the person inspecting the work, or by the appropriate supervisor.

The inspections went smoothly for each batch of rolls after the initial adjustments to documentation requirements. Field inspection emphasis was placed on the welds and surface finish by the inspector since they were a source of concern to Bethlehem's operating personnel. The surface finish requirements were challenging because selecting too rough a surface finish has the potential to scuff the product surface and increased tendency for scale pickup from the plate surface. Too smooth a requirement could potentially require post-casting surface treatment if the surface-finish smoothness could not be obtained through the casting process. With very little experience casting this alloy, surface finish capabilities were unknown. Post-casting surface treatments of this alloy were avoided because they were more challenging physically due the surface hardness, and post-treatments would result in a less cost effective and more timeconsuming process. The aim was to eliminate any post treatments.

All the rolls passed the specification requirements. While the as-cast roll's surface is somewhat aggressive, thus far it has not created any problems in processing plates to critical surface standards. 


\section{Laboratory Quality Control Tests}

Officially, this project consisted of a total of 30 rolls for installation in the Burns Harbor plant. However, because of the need to have a neutral backround of rolls, it was part of a larger study that consisted of replacing all of the 101 rolls in the furnace with nickel aluminide rolls. In total, 115 rolls were made to provide spares in the event of unexpected service failures. Data from the casting process are analyzed in terms of 110 of the roll body castings.

The intention was to use the rolls in the as-cast condition without any additional machining or grinding operations used to modify the surfaces. Consequently, the surface roughness of the rolls and its control were primary concerns in the casting process. Also, the surface roughness was a major factor in the acceptance criteria for the completed roll assemblies. The roll purchase specification requested either a surface finish of $560 \mathrm{rms}$ or better(smoother) as determined by using a C-9 Cast Microfinish Comparator (GAR Electroforming, Danbury, CT), or an alternate finish mutually agreed to by the foundry and ISG Burns Harbor. Ultimately, a surface finish was selected based on qualitative judgments. The surface finishes on the rolls was then measured using a profilometer for documentation purposes.

Other data collected for each roll body included weight of each heat, mold rotation speed, mold temperature, thickness of mold wash, pouring temperature, tap temperature, and number of heats on the furnace lining used for melting. Rings were cut from both the hot (pouring) ends and the cold ends of each of the roll body castings and they were macroetched to examine grain structure. Rockwell hardness measurements were made at six locations on each ring. The macroetched surfaces were also inspected by dye penetrant examination to determine the overall soundness of the castings and the depth of porosity measured from the outside surfaces of the castings. The chemical composition of each heat was also determined by standard analysis techniques including the concentrations in $\mathrm{wt} \%$ of aluminum, boron, carbon, chromium, copper, iron, manganese, molybdenum, nickel, phosphorous, silicon, sulfur, and zirconium.

The variation of roll body as-cast surface finish with major casting process parameters is shown in Figure 11. The scatter in the data is quite large suggesting that there was little if any dependence of surface finish on mold rotation speed, average mold temperature, mold coating thickness, or the number of heats made with the furnace lining. The variation of roll body surface finish with alloy chemical composition is shown in Figure 12. The scatter in these data is also very large. The surface roughness was plotted against the $\mathrm{Al}$ and $\mathrm{Zr}$ concentrations because these elements are the most likely to react with refractory compounds in the mold coating and thereby influence the surface finish. There is no apparent relationship between surface finish and any of the individual chemical composition variables.

In addition to the data plots of Figsure 11 and 12, neural network analysis was done to search for relationships between surface finish and the casting or compositional variables that might not be apparent from simple relationships. Neural networks are capable of identifying relationships between experimental outputs, such as the surface finish, simultaneously to several variables that otherwise appear unrelated. For example, if the surface roughness depends on the mold rotation speed and the number of heats on the furnace lining, then the neural network analysis should identify this relationship. Two neural network analyses were done. One examined the relationship between surface roughness and all of the casting process variables previously listed. The second examined the relationship between surface roughness and chemical composition. The results are presented in Figure 13. These plots compare predicted rms values determined by the neural networks to actual rms measurements. The straight lines in these two figures represent a perfect relationship between the predictions and the actual 
measurements. This would indicate a strong dependence of surface finish on the input variables. The data points, which include error bars, indicate the actual prediction results of the neural network analyses. In both cases, the agreement between predictions and actual measurements is poor.

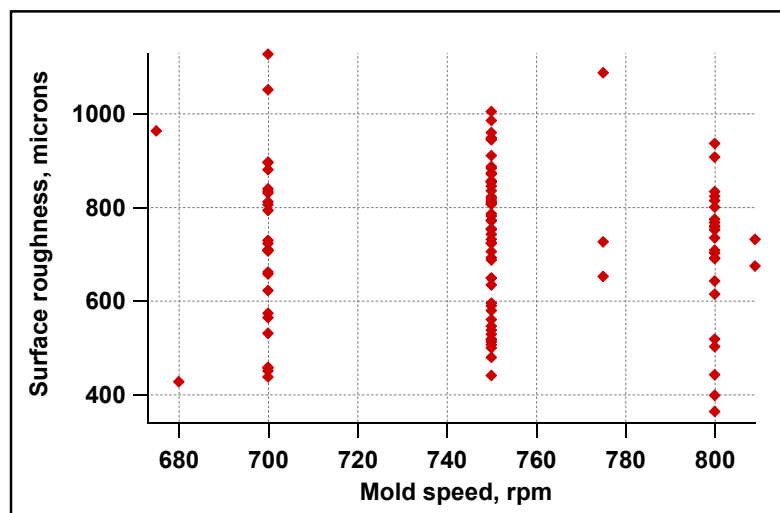

(a)

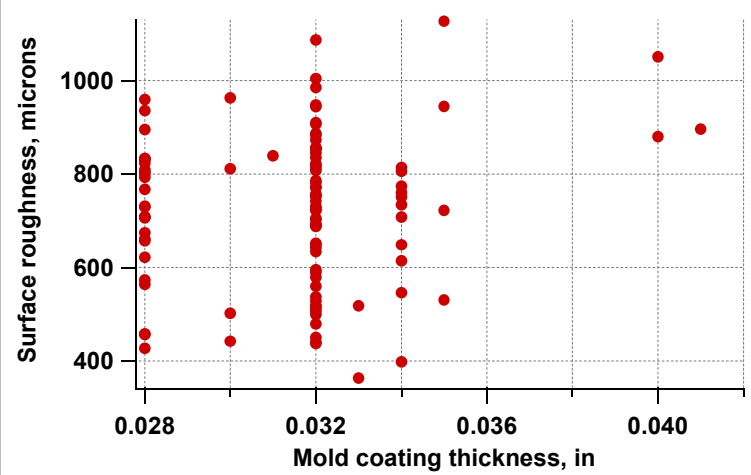

(c)

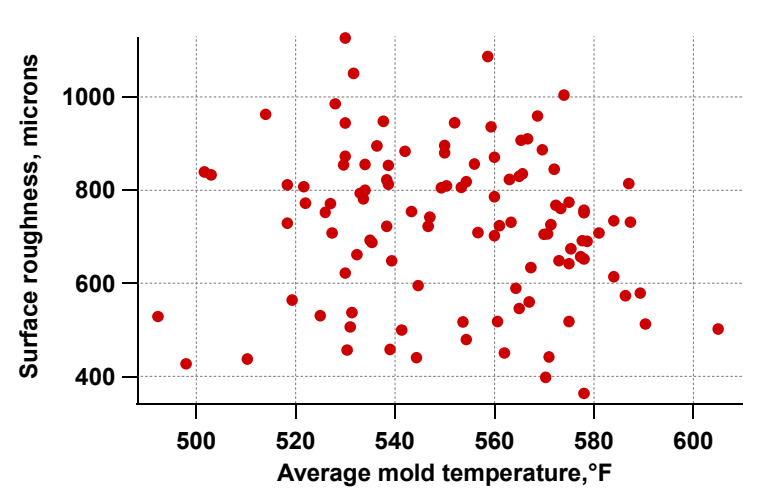

(b)

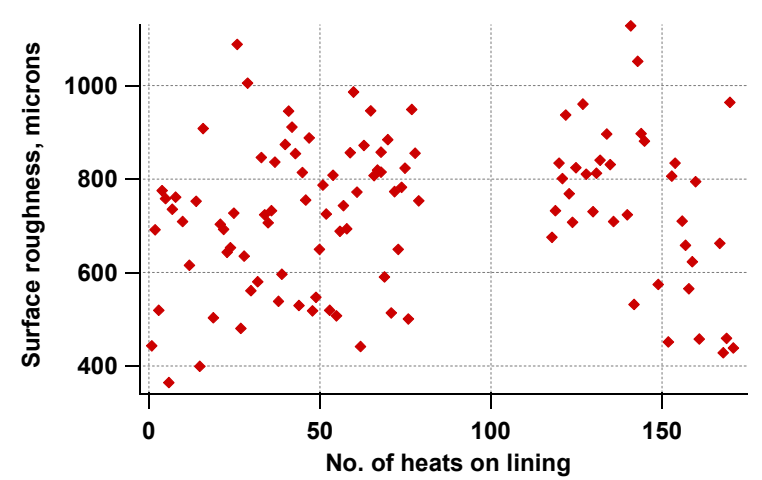

(d)

Figure 11. Variation of roll body surface roughness with (a) mold rotation speed, (b) average mold temperature, (c) mold coating (wash) thickness, and (d) the number of heats of IC221M alloys melted on the furnace lining.

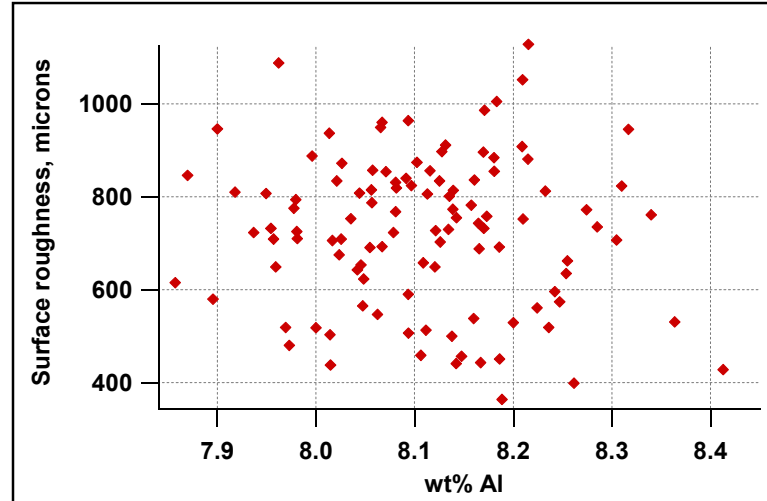

(a)

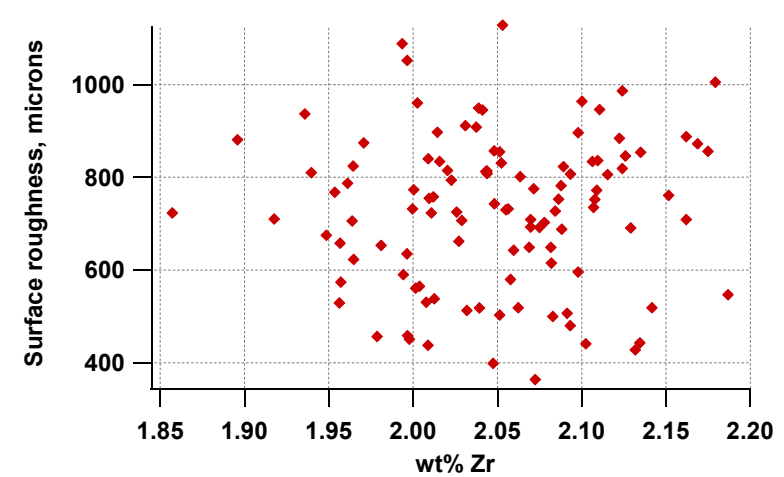

(b)

Figure 12. Variation of roll body surface roughness with (a) Al concentration, and (b) $\mathrm{Zr}$ concentration. 

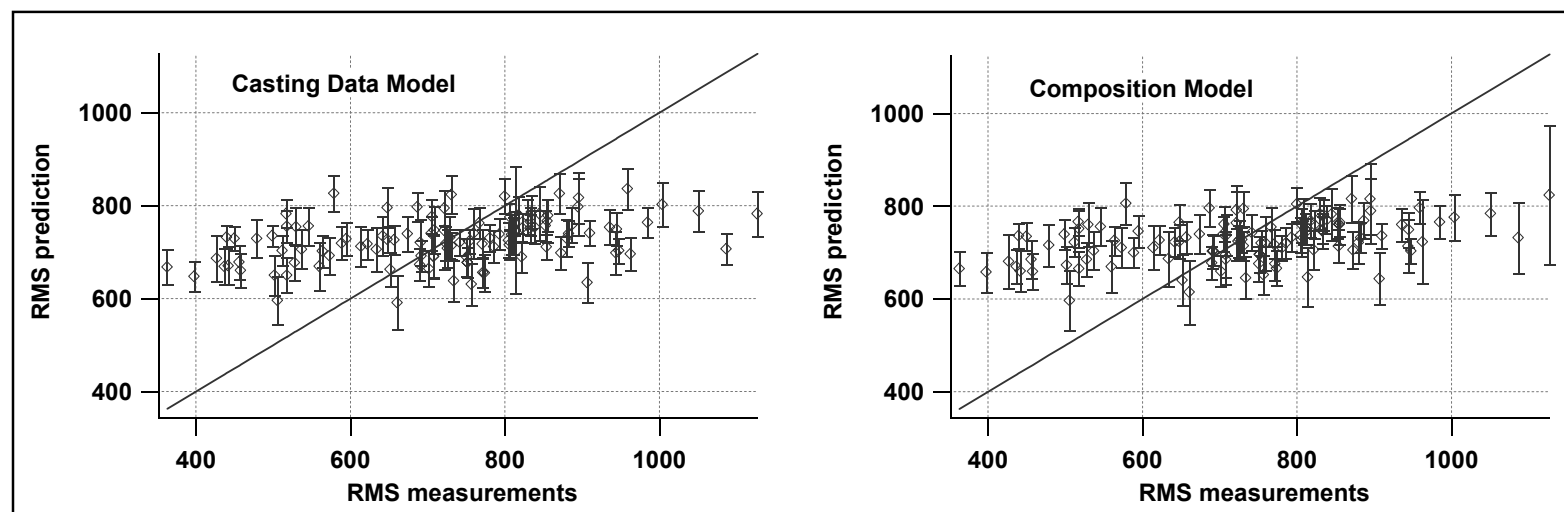

Figure 13. Results of predicted relationships between (a) casting process variables, and (b) chemical composition determined by neural network analysis.

Taken all together, the data presented in Figures 11, 12, \& 13 indicate that there is no strong relationship between any of the recorded casting process variables or chemical compositions and roll body surface roughness. Process variables that control the surface roughness appear to be unknown. Nevertheless, the surface condition of the roll bodies generally was judged to be acceptable.

The only actual mechanical property testing that was done on roll bodies made for production was Rockwell hardness testing on the cut rings used for examination of grain structure and porosity depth. The hardness data are summarized in Figure 14 which shows the distribution of average hardness values, six each, from the hot and cold ends for the entire production run of 110 castings. The distributions of hardness were similar from end to end suggesting that properties should be uniform throughout the roll bodies. The hardness values range from $R_{C}$ 25-32 which is consistent with expected hardness levels for the IC221M alloy.

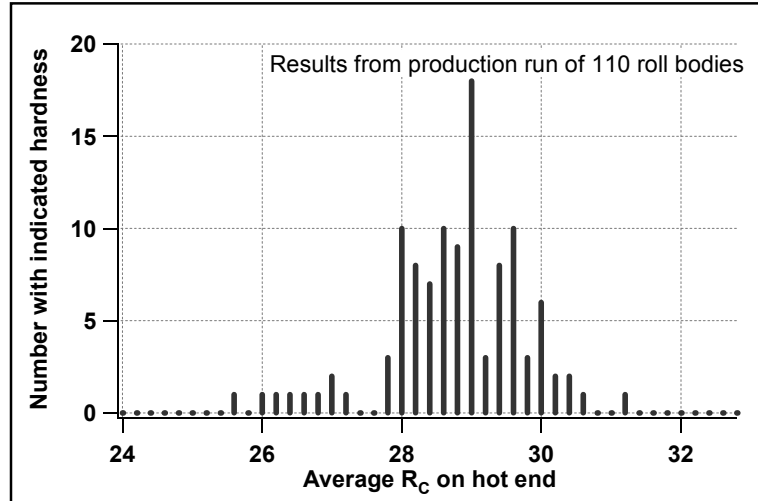

(a)

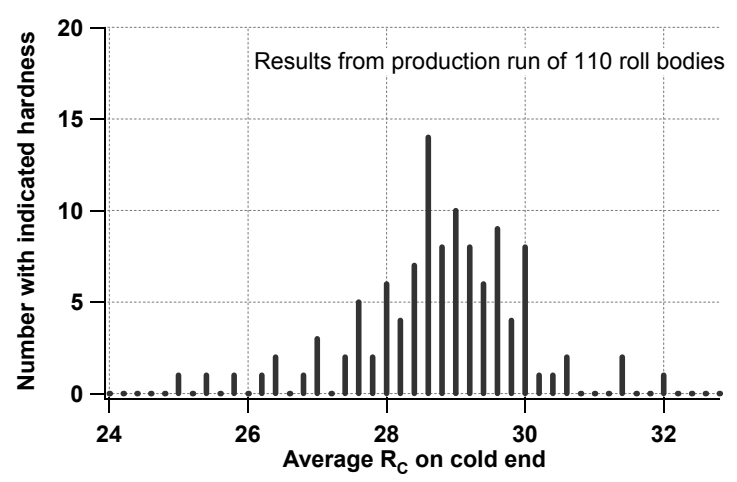

(b)

Figure 14. Distribution of average $R_{C}$ hardness values from the (a) hot (pouring) ends, and the (b) cold ends of the roll body castings. Data are shown from full production run of 110 nickel aluminide roll bodies. 


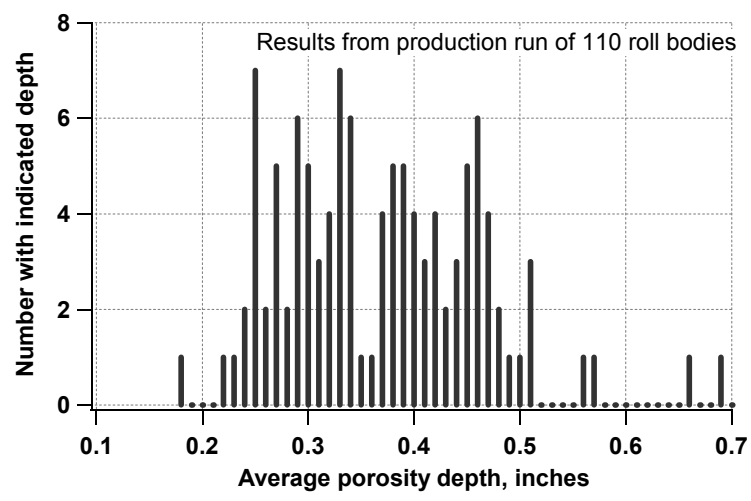

Figure 15. Distribution of maximum depth of porosity measured from the outside surface of the roll bodies.

The other characteristic of the roll bodies that could impact their properties and service performance is porosity depth. The distribution of maximum porosity depth as measured from the outside surface is shown in Figure 15. Most of the roll bodies showed porosity up to depths of 0.25-0.5 inches, with seven of the castings having indications at depths greater than 0.5 inches. These data do not indicate the size of the porosity or the number of indications at the maximum depth. Consequently, they should not be misconstrued as representative of the overall quality of the castings. On the other hand, they do suggest that additional controls could be applied in the casting process to improve overall soundness and quality of the nickel aluminide roll bodies.

A typical macrostructure of a ring taken from the roll body is shown in Figure 16(a). The transition from the columnar grain structure on the OD to equiaxed structure in the mid-wall thickness is visible in this macrostructure, and this is typical of centrifugally cast metal. Also visible are some of the centerline porosity microstructures in Figure $16(b) \& 16(c)$, which show the difference in porosity in regions near the OD and ID. As expected, the porosity is significantly higher in the region near the ID of the casting. A high-magnification micrograph in Figure 16(d) shows the details of the microstructure. 


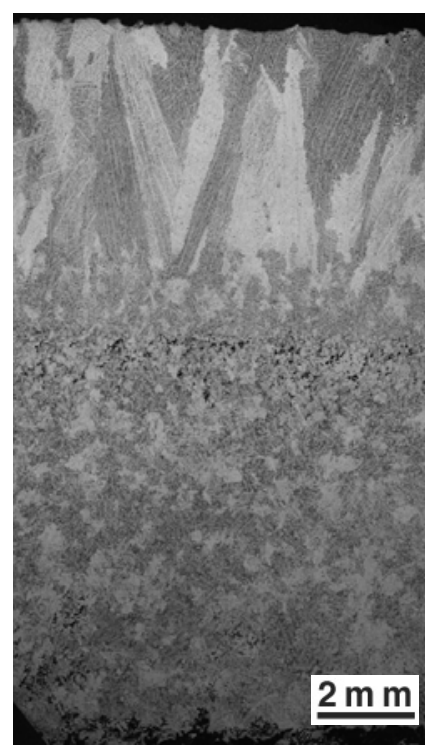

(a)

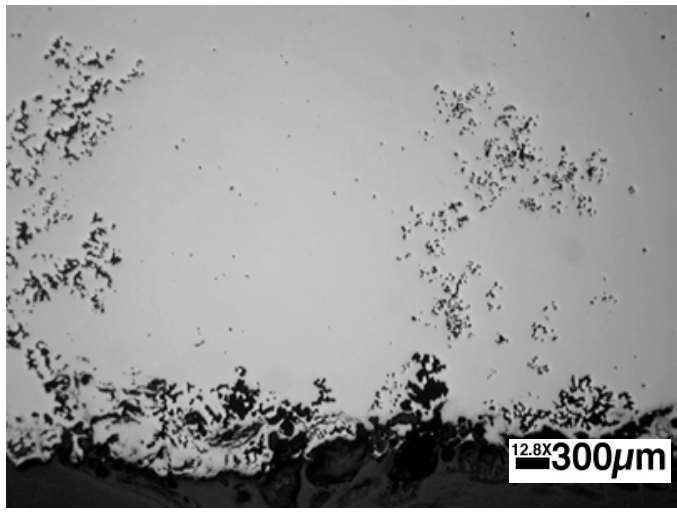

(c)

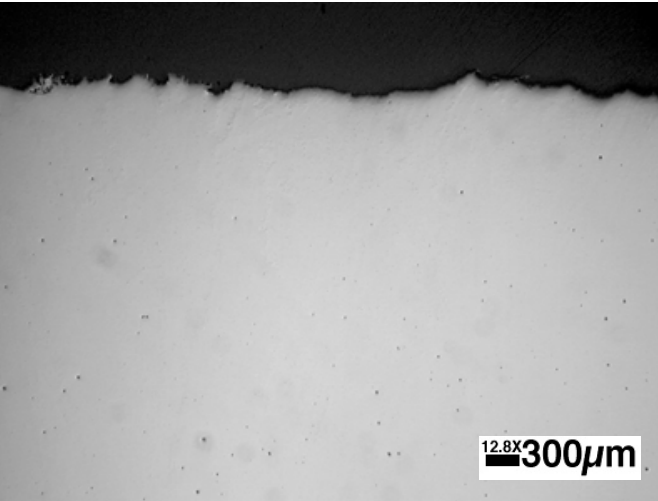

(b)

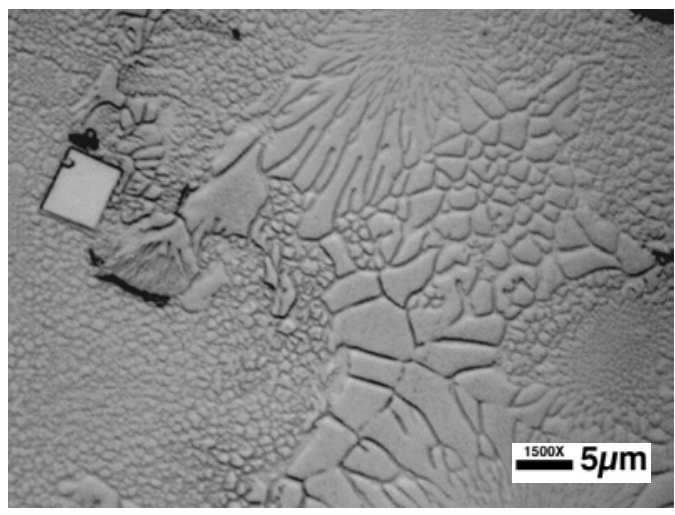

(d)

Figure 16. Macro- and microstructure of a section from the centrifugally cast roll body of IC221M: (a) macrostructure across the wall thickness, $(b)$ absence of porosity near the OD, $(c)$ presence of porosity near the ID, and $(d)$ details of microstructure.

\section{FURNACE ROLL INSTALLATION}

The thirty demonstration rolls were spread uniformly throughout the 101 roll annealing furnace, see Appendix C. Duraloy fabricated 25 of the 30 rolls. Except for the Ultra-Cast rolls, which were delivered several months after the Duraloy rolls, the rolls were installed sequentially into the furnace from the colder charge side to the hotter discharge side. New background nickel aluminide rolls were also installed at this time.

The first two demonstration rolls were installed on August 7, 2002. The rolls were generally installed within weeks of their arrival at the Burns Harbor plant. The five Ultra-Cast rolls were shipped December 20, 2002, and installed January 6, 2003, in their pre-selected positions throughout the furnace. The rolls themselves were fitted with new or refurbished bearings on each side along with new roll seals. The roll seals, while a small item, greatly 
improve the integrity of the furnace while minimizing heat loss and providing better heating uniformity of the plate product. Care was given to install the rolls without damage.

Roll installation was performed by the experienced mill maintenance group and went smoothly with no problems, see Figure 17.

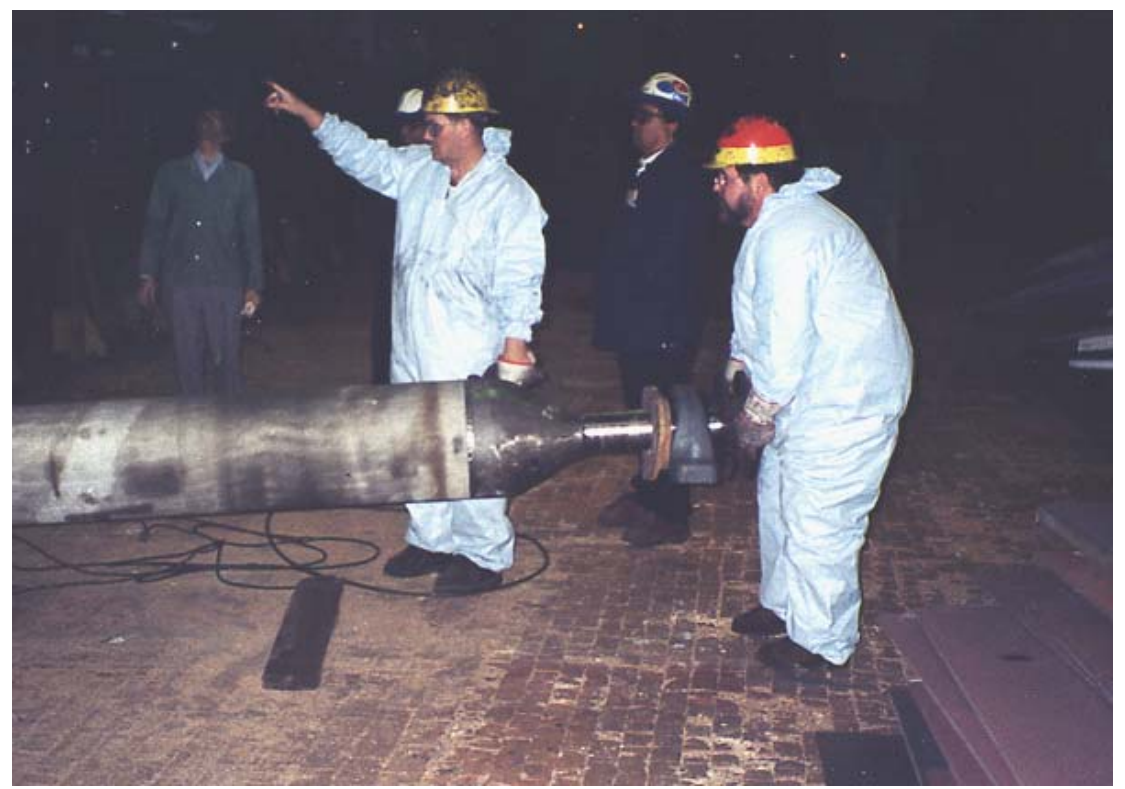

Figure 17. Nickel aluminide roll being installed in furnace by ISG maintenance crew.

\section{PLATE PROCESSING TRIALS}

The objective of these trials is to demonstrate the capabilities of a number of commercially produced new nickel aluminide intermetallic alloy rolls in a large industrial annealing furnace. The ability of these commercially produced new alloy rolls to withstand annealing process conditions while maintaining their properties over an extended period of time will determine the usefulness of this alloy. Condition of the roll surface, welds, and shape will be monitored continually to determine any change in these properties.

Another part of this objective is to demonstrate how this alloy's unique properties can be utilized to improve the annealing process by incorporating these rolls with other newly installed commercial equipment to provide an improved energy efficient furnace system, reduced environmental impact, and improved economic competitiveness. 


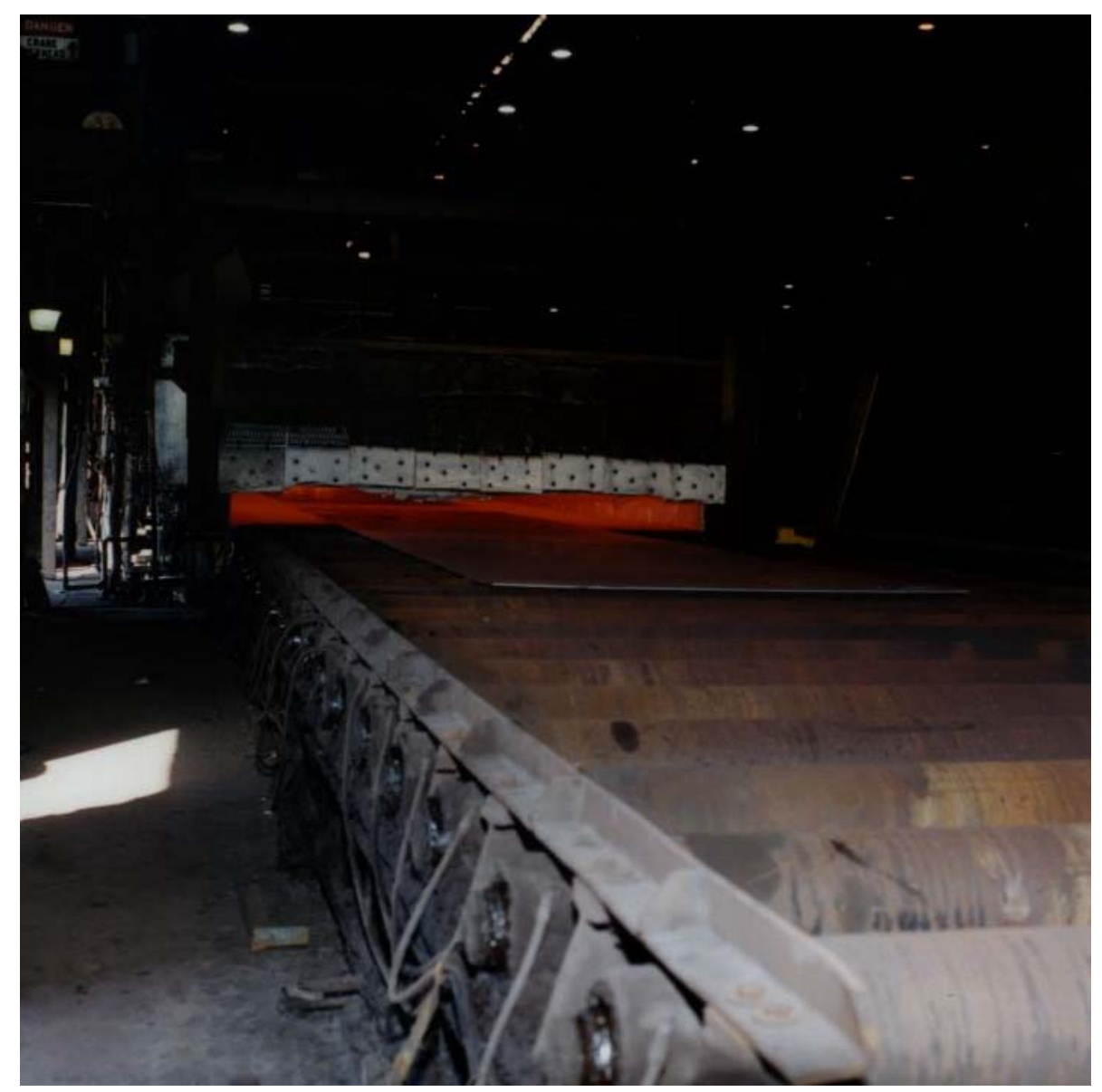

Figure 18. Steel plates entering furnace during nickel aluminide roll trials.

The demonstration trials were developed to evaluate energy consumption changes, plate surface quality improvements, and improved productivity. The project's one-year time frame requires trial completion of tests without overlapping in a very small window of opportunity. Controlling the test variables in a short time frame is challenging.

Specific trial steps:

- Collect accurate energy and tons-processed data.

- Develop valid baseline energy data immediately before trials.

- Install upgraded damper controls.

- Continuously collect energy data after damper installation.

- Collect accurate light up energy data, both before and after damper control installation.

- As operating schedule permits, operate extended campaigns of double or triple normal processing campaign lengths. (Compare any reductions in energy with light-up energy consumption to establish relationships.) 
- As operating schedule permits, perform straight-through plate processing at the slow speeds required to obtain adequate dwell time of plate in the furnace heating zones. Monitor surface condition both by mill personnel and by the customer.

- Monitor special roll surface treatment. One roll, D-24 located in the \#99 roll position, (hot end of the furnace), was belt sanded upon receipt from the supplier to note what effect this improved surface smoothness would have on the long-term surface properties.

Figure 18 shows a steel plate being processed through the furnace during these trials.

\section{FURNACE ROLL AND ENERGY PERFORMANCE}

\section{Rolls - Welds, Surface, and Physical Stability}

Continual visual observations, during and between furnace operations, shows all welds intact, no indication of wear or scale pickup on the roll surfaces, and no roll sag, blisters, or distortion after eight to twelve months of operation. This successfully completes one of the major project objectives.

The only item noted were the small green patches of scale scattered over the roll surface which began appearing soon after roll installation. This scale has had no impact to date. It appears to be a nickel oxide. Earlier experimental rolls with a very rough surface had much larger and heavier sections of scale. A concern is that longer furnace exposure may produce heavier scale that will transfer to the plate product passing over it.

The one roll with the special belt-sanded surface displays no surface difference from the other rolls.

\section{Baseline Energy Data}

Establishment of accurate baseline data is very important. Good baseline data is obtained from a process under control, and is a reflection of the typical energy consumption and processing variables before any new equipment is installed or processing trials begun. Product mix, existing equipment condition, and inadvertent changes in processing, are some of the variables that need to be considered. This energy baseline can then provide a good comparison of results after processing and equipment changes. Baseline data was obtained immediately before any trials, and then this short-term baseline data was compared with recent longer-term sets of data. Close agreement of these energy sets of data then provides confidence that the process is under control and that the baseline data accurately reflects normal operating conditions.

To this end a series of seven annealing campaigns of furnace light-up to shutdown immediately prior to the damper installation were utilized as the baseline period, January 1 to February 13, see Appendix D for operating campaign energy data. Two other longer-time periods were used for comparison - the last half of 2002, and all of 2002. The year 2002 data, taken from monthly management reports, shows a fuel rate of $2.29 \mathrm{MMBtu} /$ ton for the year, and $2.25 \mathrm{MMBtu} / \mathrm{ton}$ for the last half of 2002. These two historical data samplings matched very closely to the baseline fuel rate of $2.28 \mathrm{MMBtu} / \mathrm{ton}$, Table 3 . 


\section{Post Damper Installation Energy Data}

The effect of the damper installation was determined by collecting all the plate processing energy data taken from immediately after damper installation to the most recent data available, February 18 to July 3, 2003. The fuel rate for this period of 14 campaigns with complete data was 1.67 MMBtu/ton, a $27 \%$ reduction from baseline. It should be noted that the several months after the damper installation the fuel rate consumption declined continuously at a slow rate while adjustments and refinements were being made to the dampers. The last two

\begin{tabular}{|c|c|c|c|c|}
\hline \multicolumn{5}{|c|}{ Table 3 Trial Energy Data } \\
\hline Data Type & MMBtu & Tons & MMBtu/ton & Comments \\
\hline & & & & \\
\hline Fuel Rate - 2002 & & & 2.29 & From Mgmt. Rpt. \\
\hline Fuel Rate, $2^{\text {nd }}$ Half 2002 & & & 2.25 & From Mgmt. Rpt. \\
\hline $\begin{array}{l}\text { Fuel Rate - BASELINE,1/1/03 } \\
\text { to Damp. Install } 2 / 13 / 03\end{array}$ & 19,167 & 8,389 & 2.28 & \\
\hline $\begin{array}{l}\text { Fuel Rate, from Damper } \\
\text { Install., } 2 / 14 / 03 \text { to } 7 / 3 / 03\end{array}$ & $\mathbf{5 7 , 5 8 0}$ & 34,514 & 1.67 & $\begin{array}{l}\text { Normal rejects, } \\
\mathbf{2 7 \%} \text { fuel redn. }\end{array}$ \\
\hline $\begin{array}{l}\text { Fuel Rate, After Damper Adj., } \\
\text { 5/6/03 to } 7 / 3 / 03\end{array}$ & 23,470 & 15,498 & 1.51 & $34 \%$ fuel redn. \\
\hline & & & & \\
\hline Fuel, Light-up Turn, 1/28/03 & 237 & & & \\
\hline Fuel, Light-up Turn, 2/4/03 & 211 & & & \\
\hline Fuel, Light-up Turn, 3/10/03 & 245 & & & \\
\hline Fuel, Light-up Turn Average & 231 & & & \\
\hline Extend. Campaign, 2/18-25/03 & 6113 & 2885 & 2.12 & \\
\hline Extend. Campaign, 3/10-20/03 & 8410 & 4412 & 1.91 & \\
\hline Extend. Campaign, 3/24-31/03 & 6663 & 3840 & 1.73 & \\
\hline Extend. Campaign, 4/7-17/03 & 5956 & 4198 & 1.42 & \\
\hline Extend. Campaign, 6/17-25/03 & $\underline{4466}$ & $\underline{2834}$ & $\underline{1.58}$ & \\
\hline Extended Campaign Average & 31,609 & 18,169 & 1.74 & \\
\hline Straight-thru $-4 / 17 / 03,1^{\text {st }}$ Turn & 202 & 177 & 1.16 & Good roll-side \\
\hline Straight-thru $-4 / 24 / 03,3^{\text {rd }}$ Turn & 200 & 152 & 1.32 & plate surface \\
\hline Straight-thru Average & 402 & 329 & 1.22 & $46 \%$ fuel redn. \\
\hline Straight-thru $-4 / 25 / 03,1^{\text {st }}$ Turn & 202 & 207 & 0.98 & Tons unconfirm. \\
\hline
\end{tabular}


months that data was available, May and June 2003, may provide a more accurate reflection of the new damper benefits. The fuel rate averaged $1.51 \mathrm{MMBtu} / \mathrm{ton}$, a $34 \%$ reduction from baseline, see Table 3 for trial energy data and Appendix D for operating campaign energy data.

(It should be noted that the extended heating campaign data and the straight-through data are included in the post damper data summary. Since the extended campaign data is approximately the same as the average, it does not skew the data downward. The straight through data is very small and has minimal effect on the average.)

The upgraded dampers have a major impact on furnace energy efficiency.

\section{Extended Heating Campaign Energy Data}

The nickel aluminide rolls were expected to allow longer campaigns of light-up to shutdown, with one of the benefits being the energy savings from not having extra light-up turns. (It would also save on reduced maintenance from limited furnace thermal cycling). Three light up turns were scheduled with close attention to accurate data collection. The three light-up turns averaged 231 MMBtu, see Table 3, with a predicted three to six percent energy reduction based on double the normal processing time. Comparisons with the energy for the light-up turns were planned to note if there were additional reductions beyond the calculated $3 \%$ to $6 \%$ reduction.

With reduced annealing orders during the trials it was not cost effective to normally schedule extended turns, but five extended turns were scheduled as part of the demonstration project. The data is inconclusive in that the average of the five trials was slightly higher, $1.74 \mathrm{MMBtu} /$ ton than the average of processing after damper installation, 1.67 MMBtu/ton. This was clouded by the adjustments to the damper controls during the several months after installation and the downward energy consumption spiral. Also, some of the extended campaigns were taken shortly after the damper installation with higher than average fuel rates since damper equipment refinements had not yet begun. A more accurate assessment may be in the comparison of the last two months of available data, $1.51 \mathrm{MMBtu} / \mathrm{ton}$ for May and June 2003, with the last two extended campaigns, 1.48 MMBtu/ton for April and June 2003, Table 3 and Appendix D. This now shows a slight reduction in energy consumption, but with the small changes in energy involved, again the data is inconclusive. It is believed that the reduced light-ups are providing an energy reduction of at least $3 \%$ to $6 \%$, and it is suggested that further evaluation of extended campaigns be undertaken to verify this assumption.

\section{Straight-Through Plate Processing Energy Data}

Three straight-through processing turns were scheduled, all in April. Two of the turns show an average of $1.22 \mathrm{MMBtu} / \mathrm{ton}$. The third trial was reported to be $0.98 \mathrm{MMBtu} / \mathrm{ton}$, but the tonnage could not be verified and the data was not included. The average of the two trials is $46 \%$ below the baseline, and includes the damper reduction, Table 3. There was some concern about scuffing of the plate surface because of slight motor mismatching of the new roll drives during the trials, but a customer who received this product reported that the trials were successful. No marks or scuffs were found on the roll side of the plate.

This straight-through processing is the preferred processing method and will become the standard once all the process details and metallurgical implications have been reviewed and difficulties resolved. This processing was a major objective of the project, and while the trials to date are limited, they demonstrated the benefits of the nickel aluminide alloy. 


\section{Environmental Impact}

The environmental benefits are a direct result of the lower natural gas consumption of the new equipment and processes. This more efficient use of fuel will result in the reduction of a similar percentage of green house gases. Energy reduction trials showed energy reductions for the dampers of $27 \%$ to $34 \%$, and $46 \%$ reduction for dampers and straightthrough processing. This reduction in greenhouse gases is important to operations, both from a cleaner environment and possible necessary future emission reductions, and of the dollar value in selling these environmental credits.

This major objective was successfully completed.

\section{Cost Competitiveness}

Processing costs are an important part of competitiveness in industry. This new alloy technology, along with overall furnace system improvements, has shown the capability of reducing energy costs directly, along with lowered costs due to additional productivity and furnace availability. Maintenance costs, while difficult to quantify, are substantial and in the hundreds of thousands of dollars when considering the elimination of the shutdowns every one to three weeks to perform roll maintenance, the lower maintenance manpower costs and lost processing time costs, and a reduction in spare rolls and associated component costs. The improved plate product quality will allow processing for a wider surface-critical plate market that was unavailable in recent years, along with reduced surface-related rejects.

Energy data shows up to $34 \%$ energy reduction from baseline after the installation of upgraded furnace damper controls, (to $\sim 0.77 \mathrm{MMBtu} /$ ton of plate processed), a potential for an additional 3 to $6 \%$ energy reduction per campaign of light-up and shutdown, a $46 \%$ energy reduction from baseline for limited trials of a combination of improved damper control and straight-through plate processing, ( 1.06 MMBtu/ton of plate processed), and up to $34 \%$ reduction in greenhouse gases for improved damper control alone.

Estimated energy cost reductions for processing 100,000 tons/yr are up to $\$ 0.5$ million/yr with the new dampers alone and more than $\$ 600,000 /$ yr with straight-through processing and new damper control. A natural gas price of $\$ 6.00 / \mathrm{MMBtu}$ is assumed.

Not included in these estimates is the $34 \%$ to $46 \%$ greenhouse gas reduction, whose credits can be sold on the exchange market.

This objective was also successfully completed.

\section{POTENTIAL NICKEL ALUMINIDE ALLOY MARKET}

Non water-cooled rolls in a furnace operating below $1800^{\circ} \mathrm{F}$ are an ideal location for this nickel aluminide alloy. There are a number of furnaces and applications similar to that of Burns Harbor, not only in the steel industry but in other industries as well.

Another use can be the selective application of this type roll to replace water cooled carrying rolls outside reheat furnaces to transfer hot product from one location to another, i.e., transfer cars, tunnel furnaces, etc. Radiant tubes for continuous heating of sheet where sagging of the tube occurs, especially with "W" tube design, could benefit from the high-temperature strength of this alloy.

Air-to-air and air-to-water (or other liquid medium) heat exchangers could benefit from this alloy's resistance to erosion, selected chemicals, and impact and wear. High temperature strength and dimensional stability are other characteristics that can be matched to material needs. Possible 
applications can be tubes in air-to-air heat exchangers where high erosion of metal tubes occurs. Heaters and special application boilers, etc. may have a material match.

Other applications can be as components in non water-cooled structural items for hot areas such as furnace doors and lintels, furnace discharge plates, etc. Containers and other holding and carrying devices for small component processing in various environments could also benefit from nickel aluminide's properties.

Now that this nickel aluminide alloy has proven its ability for commercial fabrication and operation, with commercial suppliers available in the roll market, the potential for expansion into additional product and market areas is good. The market must be actively developed and supported technically to achieve near-term market expansion.

\section{DISCUSSION}

The project was completed within the required very short one year time period. As noted in the Project Management and Activity section, planning began shortly after notice of preliminary project acceptance. The milestone dates were met through the diligence and hard work of the team and support personnel. The nickel aluminide rolls have been in the furnace for a period from eight months to one year, with process trials ongoing for four months, much longer than the original estimation of a twomonth evaluation period. There were four groupings of project activity:

\section{Commercial Nickel Aluminide Rolls}

Welding process development; commercial nickel aluminide cast roll specifications; supplier selection; roll fabrication at several suppliers; field inspection; and roll material physical properties.

Furnace Equipment Upgrades

Upgraded damper controls; improved safety control equipment; and new AC roll motor drives. Processing Trials

Fuel and tons-processed data collection; continual evaluation of roll welds, surface, and shape; baseline energy data; energy data for furnace light-ups, after-damper installation, extended processing campaigns, and straight-through campaigns; and monitoring of furnace equipment and normal process to insure no interference with trials.

\section{$\underline{\text { Report }}$}

Energy and furnace data, cost benefits, and picture gathering; data organization and reduction; documentation; coordination and communication with the various groups; and the preparation of the final report including discussion, conclusions, recommendations, and summary, completed the project's technical activity.

Also part of the project was the project cost management, record keeping, and periodic cost and technical progress reporting to DOE.

The Bethlehem-ORNL team worked very well together in that the personnel or group that had the expertise or ability to accomplish a task, quickly assumed the responsibility and completed the work. Since there was much simultaneous work at several distant locations, good communications and working relationships among the joint team members enabled the various aspects of the project to blend together smoothly.

There were a number of unheralded activities that had a large impact on the success of the project. In the joining area, the quick response to the need to join the nickel aluminide roll body to a different, less expensive alloy, and specifying welding steps and techniques that allowed effective 
fabrication methods, aided greatly in keeping the price of the roll competitive with existing alloys. The training and assistance in the alloy melting and welding process areas enabled the fabrication to begin quickly and smoothly, which again greatly aided in reducing the fabrication time, which was critical to the project's success. Decisions to install the AC roll drives at the furnace, which were not originally part of the project, had a major impact in capitalizing on nickel aluminide properties while demonstrating the benefits of the alloy. Upgrading the dampers and flame safety equipment enabled all the various furnace aspects to work synergistically together in demonstrating an energy efficient furnace system that included the nickel aluminide rolls. Very rapid roll installation and schedule of trials, especially during challenging economic conditions, also aided in the speedy completion of the project.

One of the behind-the-scenes accomplishments of the project is the accumulation of a large amount of data about each roll, including the history of melting and fabrication, physical properties, furnace operating parameters, processing conditions, tons annealed, etc. This will provide background for the technical support of the alloy rolls. It would also be beneficial to the fundamental understanding of this alloy to continue to collect processing data, with analysis, to be able to better predict its lifeexpectancy, along with expanded roll operating parameters such as higher furnace and plate processing temperatures. This knowledge will aid the support of expanded nickel aluminide products and markets

The ability to commercially fabricate this new alloy and document its effectiveness as part of an energy efficient system has been recorded. Included is the saving of hundreds of thousands of dollars per year while increasing the cost competitiveness of the annealing process. It will be beneficial if these accomplishments in demonstrating the capabilities and benefits of the nickel aluminide alloy will be disseminated quickly to others both within and outside the steel industry. 


\section{CONCLUSIONS AND RECOMMENDATIONS}

- The nickel aluminide alloy maintained its properties of high temperature strength, physical stability, and erosion resistance when fabrication shifted from laboratory and experimental special processing to commercial processing.

- A welding process was developed that enabled cost-effective joining of dissimilar metals.

- After approximately one year of operation in a commercial annealing furnace, all the nickel aluminide rolls and their components are performing well.

- Incorporation of this new intermetallic alloy in the evaluation of an energy efficient furnace system resulted in up to a $34 \%$ energy reduction from baseline after the installation of upgraded furnace damper controls, along with up to a $34 \%$ reduction in greenhouse gases, potential for an additional 3 to $6 \%$ energy reduction per campaign of light-up and shutdown, and a $46 \%$ energy reduction from baseline for limited trials of a combination of improved damper control and straight-through plate processing. The limited straight-through processing provided improved plate product surfaces that will allow the additional processing of surface critical material. Benefits also include associated reductions in maintenance, reduction in spare rolls and associated component costs, and potential for greater through-put and productivity. Estimated project energy cost reductions for processing 100,000 tons/yr are almost $\$ 0.5$ million/yr with the new dampers alone and more than $\$ 600,000 / \mathrm{yr}$ with straight-through processing and new damper control, assuming natural gas prices of $\$ 6.00 / \mathrm{MMBtu}$.

- With this successful demonstration, the potential is great for the expanded utilization of this nickel aluminide alloy in many commercial applications both within and outside the steel industry.

This leads to the conclusion that this project's overall goal has been successfully completed by the demonstration of the commercially produced nickel aluminide alloy rolls as part of an updated energy efficient large commercial annealing furnace system. These alloy rolls, tied to the updated flame safety equipment, updated damper controls, and new roll drive system, have demonstrated an improved energy efficient furnace system with reduced environmental impact and improved economic competitiveness.

Recommendations are twofold:

- Consolidate the information gained from earlier experimental nickel aluminide work, and continue the collection and analysis of alloy performance data from the current plate mill roll installation. Use this information to develop life-expectancy data and expanded roll operating parameters such as higher furnace operating temperatures, i.e., obtain maximum benefit from the alloy rolls.

- Provide technical support for the broader utilization of the nickel aluminide alloy in similar applications through publicity of the alloy's performance in a commercial application, along with technical assistance in developing new alloy products and markets. 


\section{REFERENCES}

1. Aoki K, Izumi O. Nippon Kinzoku Gakkaishi 1979;43:1190.

2. Liu CT, White CL, Horton JA. Acta Metall 1985;33:213.

3. Liu CT, White CL, Lee EH. Scripta Metall 1985;19:1247.

4. Liu CT, Sikka VK. J Metals 1986;38:19.

5. Liu CT, Lee EH, McKamey CG. Scripta Metall 1989;23:875.

6. Alexander DJ, Sikka VK. Mater Sci Eng 1992;A152:114.

7. Stoloff NS, Liu CT. In: Stoloff NS et al, editor. Physical Metallurgy and Processing of Intermetallic Compounds. New York, USA: Chapman and Hall, 1996. p. 159.

8. Sikka VK. In: Welsch G et al, editor. Oxidation and Corrosion of Intermetallic Alloys. West Lafayette, USA: Purdue University, 1996, p. 1.

9. Sikka VK. In: Deevi SC et al, editor. International Symposium on Nickel and Iron Aluminides: Processing, Properties, and Applications. Materials Park, USA: ASM International, 1997, p. 361.

10. Sikka VK. Mater Sci Eng 1997;A239-240:564.

11. Santella ML In: Deevi SC et al, editor. International Symposium on Nickel and Iron Aluminides: Processing, Properties, and Applications. Materials Park, USA: ASM International, 1997, p. 321.

12. Sikka VK, Deevi SC, Vought JD. Advanced Materials and Processes 1995;147:29.

13. Sikka VK, Deevi SC. Mater Technol 1995;10:97.

14. Deevi SC. Intermetallics 2000;8:679. 


\section{APPENDIX}

A. Specifications For Nickel Aluminide (IC-221M) Transfer Rolls For 160-Inch Mill, Steel

B. Nickel Aluminide Recommended Welding Procedure

C. Nickel Aluminide Test Roll Locations in the Burns Harbor Plate Mill Annealing Furnace

D. B.H. - Nickel Aluminide Roll, Furnace Campaign Energy Data, January 1 to July 3, 2003 


\title{
APPENDIX A
}

\section{SPECIFICATION FOR \\ NICKEL ALUMINIDE (IC-221M) TRANSFER ROLLS FOR 160-INCH STEEL HARDENING (AUSTENITIZING) FURNACE}

\author{
V. K. Sikka, M. L. Santella, and P. Angelini \\ Metals and Ceramics Division
}

\section{BACKGROUND}

The transfer rolls in steel hardening furnaces are used to convey steel plates through the furnace. The furnace temperatures vary between about $1650^{\circ} \mathrm{F}$ and $1750^{\circ} \mathrm{F}$. During this operation, transfer rolls manufactured from $\mathrm{H}$-series cast austenitic alloys undergo three phenomena: roll blistering, roll sagging, and roll pickup. All of these phenomena can adversely affect the quality of the steel plates that are processed through the furnaces.

In over four years of trial study at Bethlehem Steel - Burns Harbor Plant, it has been determined that the rolls fabricated from a nickel aluminide alloy (IC-221M), a patented alloy developed at ORNL, can eliminate all of the issues listed with the H-series rolls. The purpose of this specification is to: (1) demonstrate commercial manufacturability of nickel aluminide rolls, and (2) conduct a full furnace production operation with nickel aluminide rolls. rolls.

This specification addresses the requirements for the manufacture of nickel aluminide

\section{ROLL DESIGN AND ASSEMBLY}

The configuration, dimensions including tolerances, machining requirements, and general assembly details for the hardening furnace rolls are given in Bethlehem Steel Corporation drawings \#300091 \& \#300092. The manufacturing drawings of the Seller should be consistent with the referenced drawings as amended in this specification or by mutual agreement. The Seller shall submit drawings for approval, and they shall perform all work according to the approved drawings. Likewise, the Seller shall submit all welding procedures for approval, and they shall perform all welding according to the approved procedures.

\section{CHEMICAL ANALYSIS REQUIREMENTS}

The nickel aluminide alloy for rolls is designated as IC-221M. Nominal chemical analysis of the alloy with accepted range is given in Table 1. 
Table 1. Chemical analysis of IC-221M

\begin{tabular}{|c|c|c|}
\hline \multirow{2}{*}{ Element } & \multicolumn{2}{|l|}{ Weight percent } \\
\cline { 2 - 3 } & AIM & Range \\
\hline $\mathrm{Ni}$ & Balance & Balance \\
\hline $\mathrm{Cr}$ & 7.70 & $7.50-8.50$ \\
\hline $\mathrm{Mo}$ & 1.43 & $1.30-1.80$ \\
\hline $\mathrm{Al}$ & 8.00 & $7.50-8.50$ \\
\hline $\mathrm{Zr}$ & 2.0 & $1.70-2.2$ \\
\hline $\mathrm{B}$ & 0.008 & $0.010 \mathrm{max}$ \\
\hline $\mathrm{C}$ & --- & $0.05 \max$ \\
\hline $\mathrm{Si}$ & --- & $0.1 \max$ \\
\hline $\mathrm{Fe}$ & --- & $0.3 \max$ \\
\hline $\mathrm{S}$ & --- & $0.005 \max$ \\
\hline $\mathrm{Mn}$ & --- & $0.1 \mathrm{max}$ \\
\hline $\mathrm{P}$ & --- & $0.01 \mathrm{max}$ \\
\hline $\mathrm{Cu}$ & --- & $0.3 \max$ \\
\hline
\end{tabular}

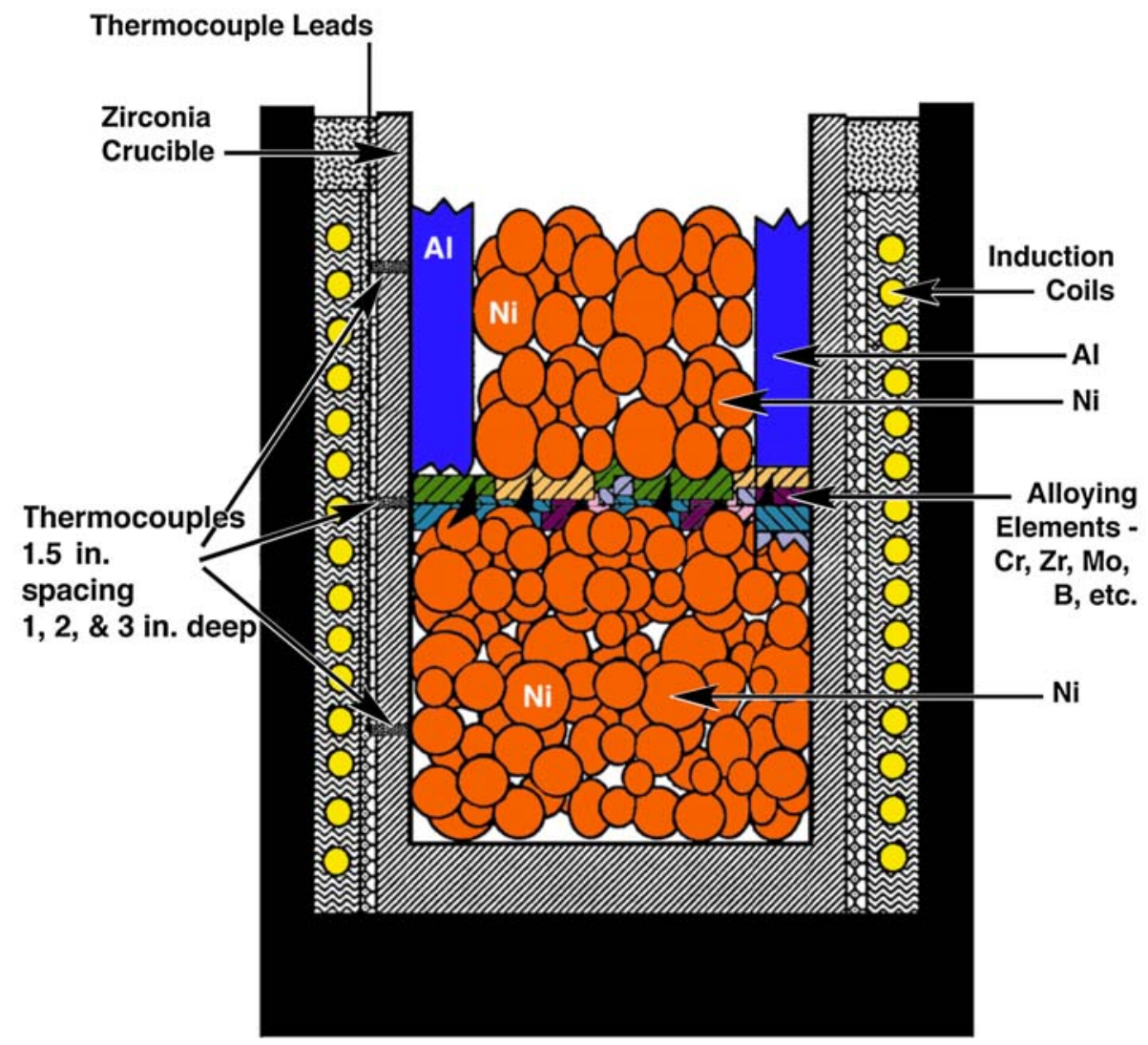

Fig. 1. Schematic of Exo-Melt ${ }^{\mathrm{TM}}$ process: special furnace-loading arrangement for melting nickel aluminide alloy IC-221M. 


\section{MELTING}

The recommended procedure for melting nickel aluminide alloy IC-221M is to use the method known as Exo-Melt ${ }^{\mathrm{TM}}$. This method was developed at ORNL for melting nickel aluminide alloys. This process uses a special furnace-loading arrangement for various alloying elements in order to maximize the use of the exothermic heat that occurs during the mixing of nickel and aluminum for melting of the alloy. An example arrangement of furnace-loading for melting the IC221 M alloy is shown in Fig. 1. The Exo-Melt ${ }^{\mathrm{TM}}$ process should be followed as closely as possible. However, the stacking sequence may be modified as needed based on actual production conditions, for example, when charging a hot induction furnace. Alloying elements such as boron, chromium, molybdenum and zirconium can be added at the best time to minimize losses based on individual manufacturer's experience.

The exotherm occurs only during the use of virgin melt stock. However, when revert is used, it still can be mixed with $50 \%$ virgin stock.

The use of Exo-Melt ${ }^{\mathrm{TM}}$ with virgin stock takes nearly half the time during induction melting as opposed to standard $\mathrm{H}$-series alloys.

- Crucibles of $\mathrm{Al}_{2} \mathrm{O}_{3}$ or $\mathrm{ZrO}_{2}$ should be used. $\mathrm{SiO}_{2}$ in the crucible refractory will react with molten IC221M during long exposures and this will result in undesirable silicon pickup in the melts. Thus, it is required to minimize the holding time in the furnace crucible.

- $\quad$ All melt stock for this procurement will be bulk. For example, nickel can be plate or balls. Aluminum can be plate, bar, or pieces cut or sheared from aluminum pigs. No turnings or chips should be used.

- The reactive elements, aluminum and zirconium, tend to oxidize and form slag. It is required that an argon cover be used during melting and that the melt be covered with insulating material such as Kaowool to minimize excessive slag formation and loss in melt temperature.

- Recovery of various elements is typically 98 to $100 \%$. The only element that requires compensation is zirconium and it should be loaded at 1.2 times the target.

- On-line chemical analysis is required for commercial manufacturing. ORNL will assist in supplying certain alloy buttons.

\section{CASTING SURFACE FINISH}

Nickel aluminide roll bodies will be used in the as-centrifugally-cast condition. The required as-cast surface finish is $560 \mathrm{rms}$ or better as determined using a C-9 Cast Microfinish Comparator available from GAR Electroforming of Danbury, CT (Phone: 203-744-4300). Alternatively, roll body surface finish may conform to internal standards of the Seller based on approval of the Company and the end user (in this case, Bethlehem Steel Corporation). 


\section{CUTTING AND MACHINING}

The nickel aluminide alloy is hard to cut and machine. The following are the recommendations for these operations:

Cutting: centrifugal cast pipe can be cut by abrasive wheel.

Machining: grinding works the best for nickel aluminides. However, if machining is needed (as is the case with weld preparation), slow cutting speeds and small depths of cut are most appropriate.

\section{TRUNNIONS}

The trunnions or end bells of the nickel aluminide transfer roll assemblies must be made of the H-series cast austenitic alloy HP or HP-modified alloy such as MO-RE 1, and AISI 309.

The trunnion can be a single unit or a welded unit where the shaft is welded to the end bell. The production and fabrication of the trunnions should adhere to well-established commercial practice.

\section{WELDING}

All rolls are to be fabricated by welding the cast roll body of IC-221M to the trunnions. Experience shows that IC-221M roll bodies that are welded to $\mathrm{H}$-series alloy trunnions with welding filler metals developed specifically for nickel aluminide alloys are capable of delivering the desired service performance. The nominal chemical compositions of the welding filler metals that are compatible with IC-221M base metal and that are recommended for the roll fabrication are shown in Table 2. The Ni20CrZr filler metal should be used for root beads, for one to two additional layers of weld deposit, and for any repairs during the assembly welding. The Ni20CrZr filler metal is ductile and chemically compatible with the IC221M base metal. The welds should be completed with the IC-221LA filler metal. See attached Fig. 3 for welding detail. These filler metals can be obtained from Stoody Company, Bowling Green, Kentucky [contact: Ravi Menon, (270) 781-9777, ext. 2009, Fax: (270) 782-9237, email: ravi_menon@thermadyne.com].

Table 2. Nominal composition of welding filler metals for welding IC221M

\begin{tabular}{|c|c|c|c|c|c|}
\hline \multirow{2}{*}{$\begin{array}{c}\text { Alloy } \\
\text { ID }\end{array}$} & \multicolumn{5}{|c|}{ Concentration (wt \%) } \\
\cline { 2 - 6 } & $\mathbf{N i}$ & $\mathbf{A l}$ & $\mathbf{C r}$ & $\mathbf{Z r}$ & Mo \\
\hline Ni20CrZr & Balance & --- & 20 & 1.5 & --- \\
\hline IC221LA & Balance & 4.5 & 16.2 & 1.5 & 1.2 \\
\hline
\end{tabular}

A detailed procedure for welding the IC221M roll bodies to H-series alloy trunnions is attached. 
The Seller should submit a detailed welding procedure for ORNL review and approval prior to initiation of any welding. ORNL staff will be available to support the welding activities as needed.

\section{Test Data}

\section{Data for each roll}

include:

For quality assurance purposes, the following test data is needed on each roll. These

1. A digital photograph showing the cut edge of both the hot and the cold cropped ends of the centrifugal castings after macro-etching.

2. Record the depth of porosity from tube ID. Data taken from cropped rings (dye check can be used for this).

3. Hardness measurements (Rockwell C or Brinell) taken at six approximately equally spaced locations around the circumferences of the edges of each cropped ring.

\section{Welder Qualification Data (not needed for each roll)}

Welder qualification is needed for each welder used on the job. Welder qualification will include:

- Welding a cropped ring of nickel aluminide to a sand cast ring of the trunnion alloy (HP) The HP ring should have the same diameter and nominal wall thickness as the end of a trunnion.

- $\quad$ Record all weld parameters for root pass and passes used to fill the cavity.

- $\quad$ Dye check the root pass and finished weld. Record size, type (cracks, porosity, etc.), and location of any external defects in or adjacent to the weld. Acceptance will be based on criteria stated in the attached welding procedure.

- $\quad$ X-ray the weld. Acceptance will be based on the latest edition of the ASME Boiler and Pressure Vessel Code, Section VIII, Division 1, Subsection B, UW-51.

\section{Tensile Data (not needed for each roll)}

Each Seller will provide room temperature tensile data taken from a cropped ring of one centrifugal cast roll. Data will be conducted according to ASTM Specification E8 and the reported data will include:

1. Yield Strength

2. Ultimate Tensile Strength 
3. Total Elongation (in 2 inches)

4. Reduction in Area

\section{Special Notes}

Both the record of welder qualification and the tensile data will be provided to Oak Ridge National Laboratory (ORNL) in the early part of the production process before proceeding with the full order. ORNL will respond with their approval within three days of receipt of the above data.

\section{ROLL BALANCING}

All fabricated rolls statically balanced using internal weights to a maximum torque of 100 pound-inch.

\section{MARKINGS}

Each of the rolls will be marked serially to maintain traceability. The following information must be associated with each transfer roll assembly:

Company Name (abbreviated)

Date Manufactured

Sequential Roll Number from the Lot

Materials such as IC-221M/IC-221LA/HP-modified/309

\section{INSPECTION} shipment.

All rolls will be subject to inspection by ORNL and Bethlehem Steel staff prior to

\section{QUALITY ASSURANCE REQUIREMENTS}

The Seller shall submit for Company's review and approval as a part of the bid package, an uncontrolled copy of their Quality Assurance (QA) Plan for the products/services being procured by the Company. The QA Plan shall be in accordance with a nationally recognized standard (e.g. ISO 9000). The Seller shall utilize its standard QA Plan requirements for the performance of the work required.

The ORNL and Bethlehem Steel Corporation reserves the right to witness any and all fabrication, assembly, or testing of the transfer rolls at any time during the manufacturing and post-manufacturing stages.

The Seller is responsible for all packing and shipping provisions to ensure that the transfer rolls arrive at the specified site in an undamaged, working condition. 
It is the Seller's responsibility to contact the Company prior to deviating from the technical requirements of this specification and from the referenced drawings (\#300091 \& \#300092). Approval for each deviation must be obtained from the Company's representative prior to deviation from the specification or drawing.

Documentation of all checks and inspections identified in this specification and the associated drawing shall be maintained by the Seller and provided to the Company's representative upon completion and prior to shipment to the specified site. In addition, a record of manufacturing details shall be compiled for each completed roll containing the information shown on pages 9-13 of this specification. The format for this information can be modified for compatibility with existing record keeping procedures of the Seller. The format of the packages should be identical for each completed roll. A copy of each specified check or inspection and of the manufacturing record shall be provided as a certification package at the time of shipment.

Certification of materials used in the manufacture of the transfer rolls shall be provided to the Company's representative upon request.

Performance Criteria: Sellers are expected to assure a level of performance of rolls fabricated by them under the furnace production conditions. The Seller assurance is expected to fix any type of failure caused by defects in materials and/or workmanship at their expense provided the failure occurs within six months after installing the roll in the furnace. Since all rolls will not be installed at one time, the Seller will only be responsible for roll performance within two years from their delivery date. This implies that if a roll is not put into service for two years from its delivery date and it fails within six months after installing in the furnace, the Seller will not be held liable for its performance assurance.

\title{
SHIPMENT
}

Completed rolls, after inspection, can be shipped in smaller lots of 10 to 15 . All rolls will be shipped to John Mengel at the following address:

\author{
Bethlehem Steel Corporation \\ Plate Mill Department \\ Door No. 7004 \\ U.S. Highway 12 \\ Burns Harbor Plant \\ Chesterton, Indiana 46304
}

Contact: Bob Petrusha

\section{QUALIFICATION OF ROLL MANUFACTURER}

Each roll supplier who bids for large lots will also be required to manufacture one complete roll. This one roll exercise will have benefit to the potential supplier in that they can become familiar with details of all of the operations needed for complete roll manufacturing. This includes melting process, centrifugal casting, cutting, machining, and welding operations. 
ORNL will use this roll to qualify both the base metal and welds for their microstructure and mechanical properties. Data on these rolls will be compared with the base line data that exist on IC-221M and IC-221LA.

Acceptance Criteria for Rolls: The acceptance criteria for nickel aluminide rolls consists of a combination of criteria, which are briefly described below.

1. Chemical Analysis: Chemical analysis of each roll must be within the specified range for IC-221M for the roll body and HP-modified and Type 309 stainless steel for the trunnion.

2. Dimensional Control: All dimensions must meet the requirements specified in the approved roll drawings.

3. Surface Finish: Rolls will be used in the as-cast condition and its surface finish must fall within the specified limit.

4. Weld Quality: Weld inspection report for each roll must show that the assembly welds conform to the acceptance criteria detailed in the attached weld procedure. The weld wire chemistry certifications must be provided for each weld.

5. Marking: Markings that uniquely identify each roll assembly must be clearly visible on the shaft end of each roll.

6. Documentation: All required documentation and inspection reports shall be signed in blue or black ink by the person completing the work, the person inspecting the work, or by the appropriate supervisor. 


\section{$\underline{\text { Seller: }}$}

Roll Body Identification: (Give identification number that will be used on the finished roll.)

\section{Roll Alloy:}

\section{Melting Record:}

Date Melted:

Furnace ID:

Operators:

Melt Stock: $\%$ virgin $\%$ revert

Melt Practice: (Information such as use of Exo-melt, addition of certain elements by ladle addition, etc.)

Melt Chemistry: (attach analysis sheet)

Melt Tapping Temperature:

Slag Removal:

\section{Centrifugal Casting Record:}

Mold ID:

Mold Wash Type Used:

Mold Wash Thickness:

Mold Treatment (baking, etc.) Prior to Pouring:

Melt Spinning Speed:

Time in Mold Prior to Removal: 


\section{Centrifugal Casting Preparation Record:}

Mold Wash Removal Treatment:

Cast Outside Diameter Surface Characteristics:

Cast ID Surface Characteristics:

Casting Length:

Casting Diameter: End One Middle End Two

Cropping of Casting to Length: Length Cut End One

Length Cut End Two

\section{Roll Fabrication Record:}

Weld Preparation of Centrifugal Casting:

Machining Method: (Details of tool, depth of cut, speed, and time)

Attach sketch of weld design.

Trunnion Details:

Alloy Type:

Chemical Analysis: (attach analysis)

Overall Quality Visual:

Weld Preparation: (Machining detail similar to centrifugal casting for comparison.)

\section{Static Casting Record}

End bell serial numbers: Side 1

Side 2 


\section{Weld Root Pass Details:}

Weld Wire Type:

Wire Supplier:

Wire Diameter:

Wire Type: (flux cored versus solid)

\section{Weld Root Pass Details: (continued)}

Weld Method:

Preheat:

Current:

Voltage:

Dye Check of Root Pass: Report observations including

- any defect?

- any grinding?

- any rewelding?

\section{Weld Cavity Fill-up Details:}

Weld Wire Type:

Wire Supplier:

Wire Diameter:

Wire Type: (powder cored versus solid) 


\section{Weld Cavity Fill-up Details (continued):}

Weld Method:

Preheat:

Current:

Voltage:

Interpass Temperature:

Number of Passes:

Dye Check Report: Root Pass Finish Passes

- Defects

- Grinding

- Rewelding

\section{Weld Details for Welded Trunnion/Shaft:}

Shaft Alloy:

Shaft Type

Cast

Wrought

Weld Design:

Weld Wire Type:

Wire Size:

Weld Method:

Preheat:

Interpass Temperature:

Current:

Voltage:

\section{Final Roll Balance:}

Method Used: 


\section{Inspector Comments and Certification:}

Comments:

Certification:

Date Completed: 


\section{BASE METALS}

Alloys: $\quad$ IC221M, nominal composition: Ni-8Al-7.7Cr-1.5Mo-1.7Zr-0.008B, wt $\%$ H-Series cast austenitic alloys such as HP, nominal composition: Fe(0.35-0.75)C-(2.00 max)Mn-(2.00 max)Si-(24-28)Cr-(33-37)Ni-(0.5 max)Mo, wt\%, or HP-modified alloys such as MO-RE 1

Specifications: Job specifications

P-Number-Group: None

Form/Thickness: $\quad$ Static and centrifugal castings, 0.5 -1-in-thick

\section{FILLER METALS}

Alloys: $\quad \mathrm{Ni} 20 \mathrm{Cr} \mathrm{Zr}$, nominal composition: $\mathrm{Ni}-20 \mathrm{Cr}-1.5 \mathrm{Zr}$, wt $\%$ IC221LA, nominal composition: Ni-16Cr-4.5Al-1.2Mo-1.5Zr-0.003B, $\mathrm{wt} \%$

Specifications: None

F- \& A-Numbers: None

Form of Filler: $\quad$ Spooled metal-powder-cored welding wire

\section{JOINT AND GROOVE PREPARATION}

Joint design: $\quad$ See attached sketches

Precautions: $\quad$ Prevent contamination of joint and adjacent base metal from any source of low-melting metals (e.g., $\mathrm{Cd}, \mathrm{Pb}, \mathrm{Sn}, \mathrm{Zn}$ ).

Thermal cutting processes: None

Pre-weld heat treatment: None

Scale and oxide: $\quad$ Remove within 0.5 in of joint on the roll body and the trunnion. Removal of up to 0.060 in of metal from the OD surfaces is permissible as long as the weld thickness complies with the attached drawing.

Foreign material: $\quad$ Remove within 2.0 in of joint.

Back gouging: $\quad$ File, grind, or machine the root of joints to remove defects. Remove foreign matter. Perform cleanliness examination.

Cleaning: $\quad$ After machining, remove excess cutting fluids by heating with and an oxyacetylene torch to $350^{\circ} \mathrm{C}$ maximum. Remove scale, oxide, or foreign matter by brushing, grinding or sanding within 0.5 in of joint. Wipe clean with acetone or alcohol. 


\section{WELD JOINT ASSEMBLY}

Fixtures: $\quad$ Provide necessary, clean fixtures to align and support parts during welding. Use temporary welds only where necessary.

Backing gas: $\quad$ Argon. Backing gas is recommended, where practical, until the weld deposit is 3/16-in-thick. Backing gas in not required for joint designs that require backing rings.

Protection: $\quad$ Provide necessary shelter of screen for weld area to exclude foreign matter, and protect against drafts that may deteriorate arc shielding.

Cleanliness examination: Immediately before welding examine groove face and adjacent base metal for foreign matter.

Tack welds: Deposit short beads equally spaced along root of joint. Clean tack welds, and taper ends and remove defects by grinding if necessary.

\section{WELDING POSITION}

Flat and vertical up.

\section{WELDING PROCESS AND EQUIPMENT}

Process and control: Gas tungsten arc welding, manual and automatic

Arc shielding gas: Argon, $99.995 \%$ pure minimum

Welding parameters: Direct, electrode negative (straight polarity) current should be used.

Typical amperage for root beads will be in the range of 100-150 $\mathrm{A}$.

Typical amperage for fill beads will be in the range of 120-220 A.

Typical arc voltage will be in the range of 6.5-12 V.

Typical welding speeds will be in the range of 4-8 inch $/ \mathrm{min}$.

Welding parameters should be adjusted for the conditions existing at the time welding as appropriate to maintain acceptable welding practices and rates.

Current source: Rectifier or generator (drooping V-A curve) with foot slope control for manual welding.

Pulsing: $\quad$ None is required, but pulsing may be used.

Arc starter: $\quad$ High frequency oscillator (touch start optional)

Electrode: $\quad$ AWS A5.12, Class EWTh-2, tungsten, diameter of 3/32 inch 


\section{PREHEAT AND INTERPASS TEMPERATURES}

Preheat temperature: Room temperature to $120^{\circ} \mathrm{C}$

Equipment: $\quad$ Oxyacetylene torch or electrical resistance heaters

Interpass temperature: $200^{\circ} \mathrm{C}$ maximum

Temperature monitor: Contact pyrometer or thermocouple

\section{WELDING OF JOINT}

Welding parameters: Avoid excessive heat input

Travel:

Upward if weld axis is not level

Travel angle: $\quad 0-15^{\circ}$

Weld bead type: $\quad$ Stringer bead with convex bead profile

Technique: $\quad$ Position torch. Start pre-flow of shielding gas to purge air from torch. Start arc at low current. When stabilized, increase arc current using foot control to desired welding current.

Feed welding rod at uniform rate into leading edge of weld puddle.

Maintain end of welding rod in shielding gas.

To stop a weld bead, continue filling weld puddle while simultaneously decreasing welding current. When puddle is at a minimum size, break arc. Maintain post-flow of shielding gas to minimize oxidation of electrode rod ends and weld beads. Remove oxidized end of welding rod before reusing.

\section{CLEANING OF WELD BEADS}

Brush individual weld beads to remove light residues. Light grinding of each layer is recommended to minimize oxide build up.

\section{PEENING}

None

\section{DEFECTS}

Before depositing each weld bead, examine groove and adjacent base metal for cracks, porosity, laminations, etc.

Examine each weld bead and each deposit layer for abnormal contour, cracks, porosity, pits, incomplete fusion, inadequate joint penetration, visible inclusions or oxides, etc. Repair such defects before proceeding.

\section{POSTWELD HEAT TREATMENT}


None

\section{ACCEPTANCE CRITERIA FOR PRODUCTION WELDS}

\subsection{Required examinations}

13.1.1 Acceptance of production welds shall be based on dye-penetrant examination (DPE) of both the root pass weld beads and the surfaces of the completed welds.

\subsection{Evaluations of Indications}

13.2.1 Mechanical discontinuities at the surface are revealed by bleeding out of the penetrant. Localized surface discontinuities such as may occur from machining marks, casting surface conditions, or surface oxides on either the base metals or the weld metal may produce similar indications that are not relevant.

13.2.2 Any indication that is believed not relevant shall be reexamined visually and by DPE to verify whether defects are present. Surface conditioning, such as brushing, chipping, grinding, or sanding for oxide removal may precede the reexamination. Broad areas of penetrant bleed-out that would mask relevant defects are unacceptable.

13.2.3 Relevant indications are discontinuities open to the surface such as cracks, seams, laps, cold shuts, laminations, porosity, and lack of fusion defects. Rounded indications are circular or elliptical with defect length equal to or less than three times defect width.

\subsection{Acceptance standards}

13.3.1 Only defects producing indications with major dimensions greater than $3 / 32$ inch shall be considered relevant.

13.3.2 Defects producing the following indications are unacceptable:

a. any cracks $3 / 16$ inch or greater in length;

b. rounded indications with major dimension greater than $1 / 8$ inch;

c. four or more rounded indications of size $3 / 32$ inch or greater in a line separated by $1 / 16$ inch or less, edge-to-edge;

d. twelve or more rounded indications of size $3 / 32$ inch or greater in any 6 inch length of weld.

\section{REPAIR PROCEDURE}

14.1 Defects that are judged as unacceptable shall be removed by grinding, chipping, sanding, or machining. 
14.2 The repair area shall be cleaned and inspected using the same procedure and technique required by the original weld. Acceptance of defect removal shall also be based on the same inspection criteria used for the original weld.

14.3 Welding of the area to be repaired shall conform to the requirements of this specification. The repair weld may be made either manually or automatically as appropriate for the size and configuration of the region being repaired.

14.4 The repair weld shall meet the acceptance criteria for the original weld.

14.5 The location and details of each repair shall be documented in the weld inspection report. 15. JOINT DESIGN

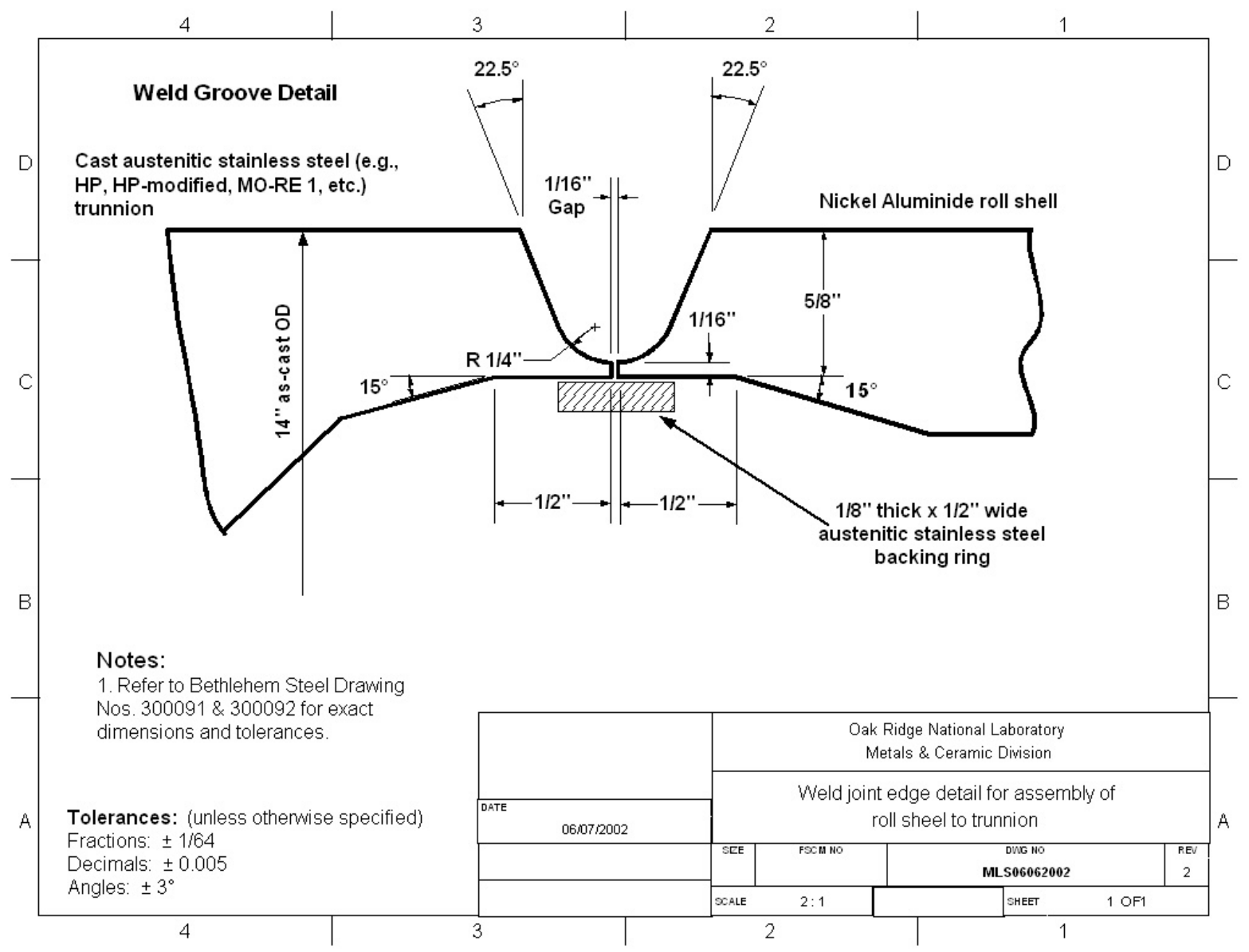




\section{APPENDIX B}

ARC Machine Program Sheet

\begin{tabular}{|c|c|c|c|c|c|c|c|}
\hline Pass Number & 1 & 2 & 3 & 4 & 5 & 6 & 7 \\
\hline Time & 999 & 999 & 999 & 999 & 999 & 999 & 999 \\
\hline Primary AVC & 6.4 & 6.6 & 6.6 & 6.6 & 6.6 & 6.6 & 6.6 \\
\hline$\overline{\text { Background AVC }}$ & 0.0 & 0.0 & 0.0 & 0.0 & 0.0 & 0.0 & 0.0 \\
\hline Primary Amps & 165 & 230 & 230 & 235 & 235 & 235 & 235 \\
\hline Background Amps & 75 & 100 & 100 & 100 & 100 & 100 & 100 \\
\hline Primary Wire & 25 & 35 & 35 & 35 & 35 & 35 & 35 \\
\hline Background Wire & 20 & 25 & 25 & 25 & 25 & 25 & 25 \\
\hline Primary Pulse & 0.35 & 0.35 & 0.35 & 0.35 & 0.35 & 0.35 & 0.35 \\
\hline Background Pulse & 0.25 & 0.25 & 0.25 & 0.25 & 0.25 & 0.25 & 0.25 \\
\hline Oscillation Amplitude & 10 & 50 & 10 & 10 & 10 & 10 & 10 \\
\hline Out Dwell & 0.10 & 0.10 & 0.10 & 0.10 & 0.10 & 0.10 & 0.10 \\
\hline Excursion Time & 0.06 & 0.06 & 0.06 & 0.06 & 0.06 & 0.06 & 0.06 \\
\hline In Dwell & 0.10 & 0.10 & 0.10 & 0.10 & 0.10 & 0.10 & 0.10 \\
\hline Travel Seed & 4.0 & 4.0 & 6.0 & 6.0 & 6.0 & 7.5 & 6.0 \\
\hline AVC Mode & SAMP & SAMP & SAMP & SAMP & SAMP & SAMP & SAMP \\
\hline Pulse Mode & ON & ON & ON & ON & $\mathrm{ON}$ & ON & ON \\
\hline Travel Step & STEP & STEP & STEP & STEP & STEP & STEP & STEP \\
\hline Pre Purge & 5 & 5 & 5 & 5 & 5 & 5 & 5 \\
\hline Start Mode & RF & RF & RF & $\mathrm{RF}$ & RF & RF & RF \\
\hline Upslope & 3.0 & 3.0 & 3.0 & 3.0 & 3.0 & 3.0 & 3.0 \\
\hline Timer Mode & MAN & MAN & MAN & MAN & MAN & MAN & MAN \\
\hline Wire Feed Pulse & $\mathrm{ON}$ & ON & ON & $\mathrm{ON}$ & ON & $\mathrm{ON}$ & $\mathrm{ON}$ \\
\hline Primary Wire Feed Delay & 0.00 & 0.00 & 0.00 & 0.00 & 0.00 & 0.00 & 0.00 \\
\hline Wire Feed Start Delay & 0.0 & 0.0 & 0.0 & 0.0 & 0.0 & 0.0 & 0.0 \\
\hline Travel Start Delay & 3.0 & 3.0 & 3.0 & 3.0 & 3.0 & 3.0 & 3.0 \\
\hline AVEC Start Delay & 1.0 & 1.0 & 1.0 & 1.0 & 1.0 & 1.0 & 1.0 \\
\hline AVC Response & 1 & 1 & 1 & 1 & 1 & 1 & 1 \\
\hline Post Purge & 10 & 10 & 10 & 10 & 10 & 10 & 10 \\
\hline Start Level & 35 & 35 & 35 & 35 & 35 & 35 & 35 \\
\hline Down SIope & 10 & 10 & 10 & 10 & 10 & 10 & 10 \\
\hline Oscillation Mode & ON & ON & $\mathrm{ON}$ & ON & $\mathrm{ON}$ & ON & $\mathrm{ON}$ \\
\hline Travel Mode & $\mathrm{CCW}$ & $\mathrm{CCW}$ & $\mathrm{CCW}$ & $\mathrm{CCW}$ & $\mathrm{CCW}$ & $\mathrm{CCW}$ & $\mathrm{CCW}$ \\
\hline Wire Feed Retract & 1 & 1 & 1 & 1 & 1 & 1 & 1 \\
\hline Wire Feed Stop Delay & 8 & 8 & 8 & 8 & 8 & 8 & 8 \\
\hline Travel Stop Delay & 10 & 10 & 10 & 10 & 10 & 10 & 10 \\
\hline AVC Stop Delay & 5 & 5 & 5 & 5 & 5 & 5 & 5 \\
\hline Stub Out & OFF & OFF & OFF & $\mathrm{OFF}$ & OFF & OFF & OFF \\
\hline
\end{tabular}

\section{Override Changes}

On the vertical upslope you need to change oscillation amplitude to 35 and

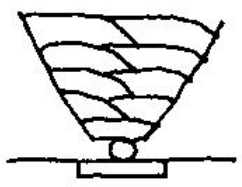
you may need to vary the primary amps and the wire feed. 
ARC Machine Program Sheet

\begin{tabular}{|l|c|c|c|c|c|c|c|}
\hline Pass Number & $\mathbf{8}$ & $\mathbf{9}$ & $\mathbf{1 0}$ & $\mathbf{1 1}$ & $\mathbf{1 2}$ & $\mathbf{1 3}$ & $\mathbf{1 4}$ \\
\hline Time & 999 & 999 & 999 & & & & \\
\hline Primary AVC & 6.6 & 6.6 & 6.9 & & & & \\
\hline Background AVC & 0.0 & 0.0 & 0.0 & & & & \\
\hline Primary Amps & 235 & 240 & 255 & & & & \\
\hline Background Amps & 100 & 100 & 100 & & & & \\
\hline Primary Wire & 35 & 30 & 40 & & & & \\
\hline Background Wire & 25 & 25 & 25 & & & & \\
\hline Primary Pulse & 0.35 & 0.35 & 0.35 & & & & \\
\hline Background Pulse & 0.25 & 0.25 & 0.25 & & & & \\
\hline Oscillation Amplitude & 10 & 10 & 60 & & & & \\
\hline Out Dwell & 0.10 & 0.10 & 0.10 & & & & \\
\hline Exclusion Time & 0.06 & 0.06 & 0.06 & & & & \\
\hline In Dwell & 0.10 & 0.10 & 0.1 & & & & \\
\hline Travel Seed & 6.0 & 5.0 & 4.5 & & & & \\
\hline AVC Mode & SAMP & SAMP & SAMP & & & & \\
\hline Pulse Mode & ON & ON & ON & & & & \\
\hline Travel Step & STEP & STEP & STEP & & & & \\
\hline Pre Purge & 5 & 5 & 5 & & & & \\
\hline Start Mode & RF & RF & RF & & & & \\
\hline Upslope & 3.0 & 3.0 & 3.0 & & & & \\
\hline Timer Mode & MAN & MAN & MAN & & & & \\
\hline Wire Feed Pulse & ON & ON & ON & & & & \\
\hline Primary Wire Feed Delay & 0.00 & 0.00 & 0.00 & & & & \\
\hline Wire Feed Start Delay & 0.0 & 0.0 & 0.0 & & & & \\
\hline Travel Start Delay & 3.0 & 3.0 & 3.0 & & & & \\
\hline AVC Start Delay & 1.0 & 1.0 & 1.0 & & & & \\
\hline AVC Response & 1 & 1 & 1 & & & & \\
\hline Post Purge & 10 & 10 & 10 & & & & \\
\hline Start Level & 35 & 35 & 35 & & & & \\
\hline Down Slope & 10 & 10 & 10 & & & & \\
\hline Oscillation Mode & ON & ON & ON & & & & \\
\hline Travel Mode & CCW & CCW & CCW & & & & \\
\hline Wire Feed Retract & 1 & 1 & 1 & & & & \\
\hline Wire Feed Stop Delay & 8 & 8 & 8 & & & & \\
\hline Travel Stop Delay & 10 & 10 & 10 & & & & \\
\hline AVC Stop Delay & 5 & 5 & 5 & & & & \\
\hline Stub Out & OFF & OFF & OFF & & & & \\
\hline
\end{tabular}

\section{Override Changes}




\section{APPENDIX C}

\begin{tabular}{|l|l|l|l|l|}
\hline & & BURNS HARBOR PLATE & & \\
\hline & & HARDENING FURNACE & & \\
\hline & & Ni3AI ROLL LOCATION & & \\
\hline & & & & \\
\hline
\end{tabular}

\begin{tabular}{|c|c|c|c|c|c|c|c|}
\hline location & roll numb & test numb & vendor & roll length & date recv & date inst & notes \\
\hline & & & & & & & \\
\hline 1 & 29123 & & duralloy & $\mathrm{L}$ & & $8 / 7 / 2002$ & \\
\hline 2 & 29133 & & duralloy & & & $8 / 7 / 2002$ & \\
\hline 3 & 29124 & & duralloy & & & $8 / 7 / 2002$ & \\
\hline 4 & 29130 & & duralloy & & & $8 / 7 / 2002$ & new drive will need $\mathrm{L}$ \\
\hline 5 & 29143 & D-1 & duralloy & & & $8 / 7 / 2002$ & \\
\hline 6 & 29134 & & duralloy & & & $8 / 7 / 2002$ & \\
\hline 7 & 29127 & & duralloy & & & $8 / 7 / 2002$ & \\
\hline 8 & 29121 & & duralloy & & & $8 / 7 / 2002$ & \\
\hline 9 & 29126 & & duralloy & & & $8 / 7 / 2002$ & \\
\hline 10 & 29120 & D-2 & duralloy & curr I & & $8 / 7 / 2002$ & \\
\hline 11 & 29125 & & duralloy & curr I & & $8 / 12 / 2002$ & \\
\hline 12 & 29146 & & duralloy & & & $8 / 9 / 2002$ & \\
\hline 13 & 29129 & & duralloy & & & $8 / 9 / 2002$ & \\
\hline 14 & 29147 & & duralloy & & & $8 / 9 / 2002$ & \\
\hline 15 & 29145 & D-3 & duralloy & & & $8 / 9 / 2002$ & \\
\hline 16 & 29144 & & duralloy & L & & $8 / 12 / 2002$ & new drive \\
\hline 17 & 29122 & & duralloy & & & $8 / 12 / 2002$ & \\
\hline 18 & 29137 & & duralloy & & & $8 / 12 / 2002$ & \\
\hline 19 & 29136 & & duralloy & $\mathrm{L}$ & & $8 / 12 / 2002$ & \\
\hline 20 & 29132 & D-4 & duralloy & & & $9 / 14 / 2002$ & \\
\hline 21 & 29183 & & duralloy & $\mathrm{L}$ & & $9 / 14 / 2002$ & \\
\hline 22 & 29191 & & duralloy & & & $9 / 14 / 2002$ & \\
\hline 23 & 29176 & & duralloy & & & $9 / 14 / 2002$ & \\
\hline 24 & 29172 & & duralloy & & & $9 / 14 / 2002$ & \\
\hline 25 & 29186 & D-5 & duralloy & & & $9 / 14 / 2002$ & \\
\hline 26 & 29189 & & duralloy & & & $9 / 14 / 2002$ & \\
\hline 27 & 29178 & & duralloy & & & $9 / 14 / 2002$ & \\
\hline 28 & 29199 & & duralloy & $\mathrm{L}$ & & $9 / 14 / 2002$ & new drive \\
\hline 29 & 29179 & & duralloy & & & $9 / 14 / 2002$ & \\
\hline 30 & 29180 & D-6 & duralloy & & & 9/14/2002 & \\
\hline 31 & 29196 & & duralloy & & & $9 / 14 / 2002$ & \\
\hline 32 & 29170 & & duralloy & & & $9 / 14 / 2002$ & \\
\hline 33 & 29160 & D-7 & duralloy & & & $9 / 29 / 2002$ & \\
\hline 34 & 29155 & & duralloy & & & 9/29/2002 & \\
\hline 35 & 29156 & & duralloy & L & & $9 / 29 / 2002$ & \\
\hline 36 & 2 & U-1 & ultracast & & & $1 / 6 / 2003$ & \\
\hline 37 & 29171 & & duralloy & & & $9 / 29 / 2002$ & \\
\hline 38 & 29169 & & duralloy & & & 9/29/2002 & \\
\hline 39 & 29177 & D-8 & duralloy & & & 9/29/2002 & \\
\hline
\end{tabular}




\begin{tabular}{|c|c|c|c|c|c|c|c|}
\hline location & roll numb & test numb & vendor & roll length & date recv & date inst & notes \\
\hline 40 & 29161 & & duralloy & & & 9/29/2002 & \\
\hline 41 & 29200 & & duralloy & $L$ & & 9/29/2002 & new drive \\
\hline 42 & 29163 & D-9 & duralloy & & & 9/29/2002 & \\
\hline 43 & 29159 & & duralloy & & & 9/29/2002 & \\
\hline 44 & 29231 & & duralloy & & & 10/13/2002 & \\
\hline 45 & 29240 & D-10 & duralloy & & & 10/13/2002 & \\
\hline 46 & 29190 & & duralloy & curr I, L & & 9/14/2002 & \\
\hline 47 & 29181 & & duralloy & curr I, L & & 10/13/2002 & \\
\hline 48 & 29209 & $D-11$ & duralloy & & & $10 / 13 / 2002$ & \\
\hline 49 & 29132 & & duralloy & & & 10/13/2002 & \\
\hline 50 & 29207 & & duralloy & & & 10/13/2002 & \\
\hline 51 & 29203 & D-12 & duralloy & & & 10/13/2002 & \\
\hline 52 & 29162 & & duralloy & & & $10 / 13 / 2002$ & \\
\hline 53 & 29235 & & duralloy & & & $10 / 13 / 2002$ & \\
\hline 54 & 5 & U-2 & ultracast & & & $12 / 30 / 2002$ & \\
\hline 55 & 29247 & & duralloy & & & $10 / 13 / 2002$ & \\
\hline 56 & 29197 & & duralloy & $\mathrm{L}$ & & $10 / 27 / 2002$ & \\
\hline 57 & 29249 & D-13 & duralloy & $\mathrm{L}$ & & $10 / 27 / 2002$ & \\
\hline 58 & 29237 & & duralloy & $\mathrm{L}$ & & $10 / 27 / 2002$ & new drive \\
\hline 59 & 29250 & & duralloy & $\mathrm{L}$ & & $10 / 27 / 2002$ & \\
\hline 60 & 29241 & D-14 & duralloy & $\mathrm{L}$ & & $10 / 27 / 2002$ & \\
\hline 61 & 29245 & & duralloy & & & $10 / 27 / 2002$ & \\
\hline 62 & 29225 & & duralloy & & & $10 / 27 / 2002$ & \\
\hline 63 & 29254 & D-15 & duralloy & & & $10 / 27 / 2002$ & \\
\hline 64 & 29252 & & duralloy & & & $10 / 27 / 2002$ & \\
\hline 65 & 29232 & & duralloy & & & $11 / 10 / 2002$ & \\
\hline 66 & 29244 & $D-16$ & duralloy & & & $11 / 10 / 2002$ & \\
\hline 67 & 29202 & & duralloy & & & $11 / 10 / 2002$ & \\
\hline 68 & 29138 & & duralloy & & & $11 / 10 / 2002$ & \\
\hline 69 & 29158 & D-17 & duralloy & & & $11 / 10 / 2002$ & \\
\hline 70 & 29219 & & duralloy & & & $11 / 10 / 2002$ & \\
\hline 71 & 29185 & & duralloy & & & $11 / 10 / 2002$ & \\
\hline 72 & 3 & U-3 & ultracast & & & $12 / 30 / 2002$ & \\
\hline 73 & 29201 & & duralloy & & & $11 / 10 / 2002$ & \\
\hline 74 & 29253 & & duralloy & & & $11 / 10 / 2002$ & \\
\hline 75 & 29154 & D-18 & duralloy & & & $11 / 24 / 2002$ & \\
\hline 76 & 29194 & & duralloy & curr I, L & & $11 / 24 / 2002$ & new drive \\
\hline 77 & 29151 & & duralloy & $\mathrm{L}$ & & $11 / 24 / 2002$ & \\
\hline 78 & 29215 & D-19 & duralloy & & & $11 / 24 / 2002$ & \\
\hline 79 & 29205 & & duralloy & & & $11 / 24 / 2002$ & \\
\hline 80 & 29227 & & duralloy & & & $11 / 24 / 2002$ & \\
\hline 81 & 29248 & D-20 & duralloy & & & $11 / 24 / 2002$ & \\
\hline 82 & 29198 & & duralloy & curr I,L & & $11 / 24 / 2002$ & \\
\hline 83 & 29251 & & duralloy & $\mathrm{L}$ & & $11 / 24 / 2002$ & \\
\hline 84 & 29234 & & duralloy & & & $11 / 24 / 2002$ & \\
\hline 85 & 4 & $U-4$ & ultracast & & & $1 / 6 / 2003$ & \\
\hline 86 & 29208 & & duralloy & & & $11 / 10 / 2002$ & \\
\hline 87 & 29221 & D-21 & duralloy & & & $12 / 9 / 2002$ & \\
\hline
\end{tabular}




\begin{tabular}{|c|c|c|c|c|c|c|c|}
\hline location & roll numb & test numb & vendor & roll length & date recv & date inst & notes \\
\hline 88 & 29226 & & duralloy & & & $12 / 9 / 2002$ & \\
\hline 89 & 29211 & & duralloy & & & $12 / 9 / 2002$ & \\
\hline 90 & 29204 & D-22 & duralloy & $\bar{L}$ & & $12 / 9 / 2002$ & \\
\hline 91 & 29214 & & duralloy & $\mathrm{L}$ & & $12 / 9 / 2002$ & \\
\hline 92 & 29242 & & duralloy & L & & $12 / 9 / 2002$ & new drive \\
\hline 93 & 29210 & D-23 & duralloy & $\mathrm{L}$ & & $12 / 9 / 2002$ & \\
\hline 94 & 29238 & & duralloy & $\bar{L}$ & & $12 / 9 / 2002$ & \\
\hline 95 & 29236 & & duralloy & & & $10 / 27 / 2002$ & \\
\hline 96 & 1 & $U-5$ & ultracast & & & $1 / 6 / 2003$ & \\
\hline 97 & 29212 & & duralloy & & & $12 / 10 / 2002$ & \\
\hline 98 & 29222 & & duralloy & & & $12 / 10 / 2002$ & \\
\hline 99 & 29142 & D-24 & duralloy & & & $12 / 10 / 2002$ & belt sanded \\
\hline 100 & 29216 & & duralloy & & & $12 / 10 / 2002$ & \\
\hline 101 & 29213 & D-25 & duralloy & & & $12 / 10 / 2002$ & \\
\hline & & & & & & & \\
\hline & & & & & & & \\
\hline & & & & & & & \\
\hline & & & & & & & \\
\hline & & & & & & & \\
\hline & & & & & & & \\
\hline & & & & & & & \\
\hline & & & & & & & \\
\hline & & & & & & & \\
\hline & & & & & & & \\
\hline & & & & & & & \\
\hline & & & & & & & \\
\hline & & & & & & & \\
\hline & & & & & & & \\
\hline & & & & & & & \\
\hline & & & & & & & \\
\hline \multirow{2}{*}{\multicolumn{4}{|c|}{\begin{tabular}{|l}
$L=$ long roll for 15 drive arrangement \\
curr I= long roll for current drive arrangement
\end{tabular}}} & & & & \\
\hline & & & & & & & \\
\hline \multicolumn{4}{|c|}{ new drive $=7$ drive arrangement } & & & & \\
\hline
\end{tabular}




\section{APPENDIX D}

\begin{tabular}{|c|c|c|c|c|}
\hline \multicolumn{5}{|c|}{ Annealing Furnace, 2003 Campaign Energy Data } \\
\hline Campaign Dates & MMBtu & Tons & MMBtu/ton & Comments \\
\hline $1 / 02-04$ & 2051 & 1297 & 1.58 & \\
\hline $1 / 8-11$ & 3417 & 1417 & 2.41 & \\
\hline $1 / 13-15$ & 1811 & 778 & 2.33 & \\
\hline $1 / 21-25$ & 2612 & 1312 & 1.99 & \\
\hline $1 / 28-31$ & 2922 & 1030 & 2.84 & \\
\hline $2 / 4-8$ & 4267 & 1614 & 2.64 & \\
\hline $2 / 9-11$ & 2088 & $\underline{941}$ & 2.22 & \\
\hline AVERAGE - BASELINE & 19,168 & 8389 & 2.28 & \\
\hline \multicolumn{5}{|l|}{ 2/11-17 DAMPER INSTALL. } \\
\hline 2/18-25, Extended Campaign & 6113 & 2885 & 2.12 & \\
\hline $3 / 3-7$ & 3769 & 1859 & 2.02 & \\
\hline 3/10-20, Extended Campaign & 8410 & 4412 & 1.91 & \\
\hline 3/24-31, Extended Campaign & 6663 & 3840 & 1.73 & \\
\hline \multicolumn{5}{|l|}{ 4/1-3 INCOMPLETE DATA } \\
\hline 4/7-17, Extended Campaign & 5956 & 4198 & 1.42 & \\
\hline $4 / 21-26$ & 3199 & 1822 & 1.75 & \\
\hline \multicolumn{5}{|l|}{ 4/29-5/3 INCOMPLETE DATA } \\
\hline $5 / 6-10$ & 2905 & 2185 & 1.33 & \\
\hline $5 / 13-17$ & 3146 & 2080 & 1.51 & \\
\hline $5 / 19-24$ & 3278 & 2028 & 1.62 & \\
\hline $5 / 27-31$ & 2587 & 1859 & 1.39 & \\
\hline $6 / 2-7$ & 3049 & 1917 & 1.59 & \\
\hline $6 / 10-14$ & 2366 & 1437 & 1.65 & \\
\hline 6/17-25, Extended Campaign & 4466 & 2834 & 1.58 & \\
\hline 3/30-7/3 & $\underline{1673}$ & $\underline{1158}$ & $\underline{1.44}$ & \\
\hline \multirow[t]{3}{*}{ 2/18-7/3/03 AVERAGE } & $\mathbf{5 7 , 5 8 0}$ & 34514 & 1.67 & $0.61 \mathrm{MMBtu} / \mathrm{ton}$ \\
\hline & & & & redn. from base, \\
\hline & & & & $27 \%$ reduction \\
\hline \multirow[t]{3}{*}{ 5/6-7/3/03 AVERAGE } & 23,470 & 15,498 & 1.51 & $0.77 \mathrm{MMBtu} /$ ton \\
\hline & & & & redn. from base, \\
\hline & & & & $34 \%$ reduction \\
\hline
\end{tabular}

